\title{
VICENTE MAROTTA RANGEL - VIDA E OBRA. DIREITO INTERNACIONAL NAS ARCADAS
}

\author{
VICENTE MAROTTA RANGEL - LIFE AND WORK. INTERNATIONAL LAW IN THE "ARCADAS"
}

\section{Paulo Borba Casella*}

\begin{abstract}
Resumo:
O exame da evolução do ensino do Direito Internacional nas Arcadas tem marco relevante com a contribuição de Vicente Marotta Rangel, que se estende por décadas, e abrange o crucial período em que, por influência do regime militar, o ensino da disciplina se tornou optativo em muitos cursos de Direito, em todo o país, mas graças a ele, nunca se interrompeu em nossa Faculdade. $\mathrm{O}$ artigo examina a longa e profícua trajetória e as principais obras do mestre, que completou 90 anos em março de 2014, e foi homenageado em dezembro do mesmo ano, com Seminário Internacional sobre Direito do Mar.

Palavras-chave: Direito internacional. Direito do mar. RANGEL, Vicente Marotta (1924 -). Ensino do Direito Internacional na Faculdade de Direito da USP.
\end{abstract}

\begin{abstract}
:
The review of the evolution of teaching of international law at the "Arcadas", as the Law School of the University of São Paulo is well-known, has a relevant boundary due to the contribution of Vicente Marotta Rangel for decades, which comprehends a crucial period which, due to the influence of the armed forces rule, the teaching of international law became an optional subject in many law courses in the entire country. However, thanks to him, it was never interrupted in this Law School. The paper examines his long, fruitful life and the main publications of this master, who reached 90 years-old in March 2014, and received in December of the same year an International Colloquium on the Law of the Sea as a tribute.
\end{abstract}

Keywords: International law. Law of the sea. RANGEL, Vicente Marotta (1924-). Teaching International Law at the São Paulo University Law School.

A oportunidade de homenagear VMR, pelos seus 90 anos, completados em março de 2014, nos permite contemplar o belo conjunto de sua trajetória intelectual e de vida; é privilégio deste poder contar mais de seis décadas, dedicadas ao estudo e à docência do Direito Internacional. É oportuna e necessária, na obra de VMR, a percepção da evolução histórica do Direito. Como modo de se estudar e de se compreender o fenômeno jurídico internacional. Para compreender o contemporâneo é preciso entender

\footnotetext{
* Professor Titular de Direito Internacional Público, Chefe do Departamento de Direito Internacional e Comparado e da Comissão de Publicação da Revista da Faculdade de Direito da Universidade de São Paulo. 
o que veio antes e poder conferir coerência ao conjunto, mediante a compreensão do que precede, para se chegar ao ora existente e daí para o que poderá vir a seguir.

Foi belo e longo o caminho, percorrido pelo ensino do Direito Internacional, em nossa escola, desde a aula inaugural de J. M. Avelar Brotero, em 1828, e as décadas durante as quais o nosso primeiro titular, da então cadeira de "Direito Eclesiástico, Diplomático e das Gentes" a regeu, até o momento presente: o leque de matérias se ampliou, como também se deu com a internacionalização da vida, no contexto pósmoderno. O que sequer precisa ser enfatizada - todos percebem.

Vicente Marotta Rangel, bacharel em Direito pela Faculdade de Direito da Universidade de São Paulo, em 1946, é doutor em Direito Internacional pela Universidade de Paris, em 1950. Auxiliar de ensino em 15 de setembro de 1954; livre-docente em 28 de junho de 1955; professor-assistente contratado em $1^{\circ}$ de janeiro de 1960; professorassistente nomeado em 26 de março de 1965; rege a cadeira, interinamente, bem como o curso de organizações internacionais a partir de outubro de 1965.

Em 1964 e 1965, em relação ao Direito Internacional Público, conforme registros dos programas lecionados nesta casa, consta o "programa do Prof. Braz de Souza Arruda, adotado pelo Dr. Vicente Marotta Rangel, na regência da cátedra". ${ }^{1}$ Acede à cátedra em 1966. De 1966 em diante este regerá a cátedra de Direito Internacional Público.

Vicente Marotta Rangel rege a cátedra de Direito Internacional Público de 1966, até aposentar-se, em 1994. Como aluno da graduação em Direito, de 1978 a 1982, lembro-me de todos os anos, ir o prof. Marotta Rangel, para Montego Bay, na Jamaica, em missão, na delegação brasileira, para a negociação, na III Conferência para a codificação do Direito do Mar. Lembro-me, também, ter sido convidado pelo prof. VMR a participar informalmente de suas aulas de pós-graduação, quando eu ainda era aluno da graduação. Foi, durante quatro anos, diretor desta Faculdade. Foi também o Coordenador de atividades culturais da CODAC - USP - o que corresponderia ao atual cargo de Próreitor de cultura e extensão.

Ministrou curso na Academia de Direito Internacional, na Haia, sobre $A$ plataforma continental na Convenção de 1982 sobre o Direito do Mar (1985). ${ }^{2}$ Ministrou

\footnotetext{
1 Não há exemplar de Anuário para 1967. V. QUEIROZ FILHO, Manoel Elpídio Pereira de. Faculdade de Direito / Largo de São Francisco: turmas de 1949, 1950 (turma do Ano Santo), 1951 e Agregados. Espírito acadêmico, tipos, picardias e estudantadas. São Paulo: Faculdade de Direito, 2009; no capítulo 'Turma do diretor - o professor Arrudinha', p. 103-107 a respeito: "O Arrudinha, nosso querido mestre e patrono da turma de 50, nosso professor no $4^{\circ}$ ano, era estourado. Todos, catedráticos, alunos e funcionários, tinham medo dele. Quando explodia era um Deus-nos-acuda. Diziam as más línguas que era doido varrido."

2 RANGEL, Vicente Marotta. Le plateau continental dans la Convention de 1982 sur le droit de la mer. Recueil de Cours, v. 5, n. 194, p. 269-428, 1985. p. 273-427.
} 
curso Solução pacífica de controvérsias, no curso de Direito Internacional, organizado pela OEA - Organização dos Estados Americanos, no Rio de Janeiro, em 1985. ${ }^{3}$

A sua extensa e relevante produção conta dezenas de publicações, ${ }^{4}$ no Brasil e no exterior. ${ }^{5}$ Conforme registros em nossa biblioteca.

A tanto se soma o papel destacado, no cenário nacional e internacional, como Juiz do Tribunal Internacional para o Direito do Mar, em Hamburgo, desde 1996, e o levaram a ser distinguido com os títulos de doutor honoris causa, pela Faculdade de Direito da Universidade de Coimbra, em 2000, bem como de professor emérito, concedido pela Congregação da Faculdade de Direito da Universidade de São Paulo, em $2006 .{ }^{6}$

Foi sucedido V. Marotta Rangel, em nossa cadeira, por Guido Fernando da Silva Soares (1937-2005). E da qual, desde 2007, me cabe assegurar a continuidade e a evolução do trabalho.

A Vicente Marotta Rangel coube aliar a pesquisa, docência e a experiência prática, como negociador brasileiro no Direito Internacional do Mar, e como Juiz do Tribunal Internacional para Direito do Mar. E prossegue, em sua atuação como docente, como juiz, e em sua produção intelectual. A Guido Soares, por sua vez, coube atuar no segmento e contribuir para o desenvolvimento entre nós do Direito Internacional do Meio Ambiente, e neste deixar registro de sua relevante atuação.

RANGEL, Vicente Marotta. Solução pacífica de controvérsias. In: COMITÊ Jurídico Interamericano (Org.) XI curso de derecho internacional. Washington, D.C.: OEA, 1985. p. 29-49.

4 RANGEL, Vicente Marotta. Direito e relações internacionais. 8. ed. São Paulo: Revista dos Tribunais, 2005; RANGEL, Vicente Marotta. L'avis consultatif du 9 juillet 2004 et l'antinomie entre volontarisme et solidarisme. In: International law and the use of force at the turn of centuries: essays in honour of Vladimir-Djuro Degan. Rijeka: Faculty of Law, Univ. of Rijeka, 2005. p. 199-205; RANGEL, Vicente Marotta. A experiência da conferência da ONU e a Convenção sobre direito do mar. In: NAZO, Georgette N. (Coord.) Questões importantes referentes ao mar. São Paulo: Soamar, 1996. p. 11-18; RANGEL, Vicente Marotta. Objetos culturais: o recente projeto UNIDROIT de convenção internacional. In: BAPTISTA, L. O.; HUCK, H. M.; CASELLA, P. B. (Org.). Direito e comércio internacional: tendências e perspectivas: estudos em homenagem ao prof. Irineu Strenger. São Paulo: LTr, 1994. p. 213-220; RANGEL, Vicente Marotta. Sobre la efectividad de la justicia en las relaciones internacionales. In: RAMA-MONTALDO, Manuel (Dir.). El derecho internacional en un mundo en transformación: liber amicorum en homenaje al profesor Eduardo Jiménez de Aréchaga. Montevideo: Fundación de Cultura Universitaria, 1994. p. 173179; RANGEL, Vicente Marotta. L'equité en droit international: des développements récents. Tessaloniki: Aristoteleio Panepistimio, 1989. p. 937-950. (separata); RANGEL, Vicente Marotta. O direito do mar e a sua unificação legislativa entre países de língua portuguesa. In: Estudos em homenagem ao professor A. Ferrer-Correia. Coimbra: Univ. de Coimbra, 1986. v. 1, p. 69-90; RANGEL, Vicente Marotta. Solução pacífica de controvérsias. In: COMITE Jurídico Interamericano (Org.) XI curso de derecho internacional. Washington, D.C.: OEA, 1985. p. 29-49.

5 BAPTISTA, Luiz Olavo; FONSECA, José Roberto Franco da (Coord.). O direito internacional no terceiro milênio: estudos em homenagem ao professor Vicente Marotta Rangel. São Paulo: LTr, 1998. p. 17-24. esp. p. 17-24, para as referências bio-bibliográficas.

${ }^{6}$ Há anos não concedia tal distinção a Congregação da Faculdade de Direito da Universidade de São Paulo. 
O estudo e o ensino do Direito Internacional Ambiental também foi entre nós iniciado por Marotta Rangel, como sempre lembra e frisa a Profa. Elisabeth de Almeida Meirelles, que tem, entre nós, assegurado a continuidade do ensino e da pesquisa nesse importantíssimo campo do Direito Internacional - e que por si representa um universo em expansão.

Em 2012, creio, durante uma das muitas temporadas em que, durante o mandato como vice-diretor, desde março de 2010 até março de 2014, estive no exercício da diretoria desta Faculdade de Direito, tive a satisfação de receber os colegas, formados na turma de 1946, para tomarem café com o diretor. Dentre os quais, veio ao gabinete o prof. VMR: os elogios que este fez, a meu respeito, aos seus colegas, sou muito grato a ele, mas não são para ser repetidos.

Desde 2008, passa a ser o nosso "Departamento de Direito Internacional e Comparado". Esta missão de ensinar o Direito Comparado se agrega ao conjunto, como proposta de ênfase na formação ampla e na perspectiva culturalmente abrangente, para a docência e a pesquisa destes campos do saber jurídico, sob nova direção.

Da relevante lição de VMR, fica o legado: nunca deixou de apoiar e defender o ensino do Direito Internacional - e nosso departamento, na docência e pesquisa nessas matérias, nas duas cadeiras e mais a terceira, de Direito do Comércio Internacional, que às primeiras foi agregada, no início dos anos noventa. ${ }^{7}$

A construção de escola de Direito Internacional nas Arcadas se fez ao longo destes mais de 180 anos, transcorridos desde a lição inaugural de Avellar Brotero, em $1^{\circ}$. de março de 1828. As lições a serem extraídas dessa trajetória são múltiplas e são muito ricas. $^{8}$ Podem ser levadas em conta, pelos pósteros. ${ }^{9}$

\footnotetext{
7 Não cobrem estas todo o escopo do que se pode denominar "assuntos internacionais" e se cria, em separado, na Universidade de São Paulo, instituto destinado ao ensino das assim chamadas "relações internacionais", ora sob a competente e inovadora gestão do professor titular Pedro Bohomoletz de Abreu Dallari. Essas cadeiras expressam escolhas políticas e de gestão universitária - e isso apesar das objeções possíveis quanto à medida na qual sejam estas realmente representativas, enquanto objeto da codificação feita.

8 CASELLA, P. B. ABZ ensaios didáticos. Prefácio de João Grandino Rodas. São Paulo: Imprensa Oficial, 2008; "Faculdade enquanto possibilidade - o papel do Largo de São Francisco"). Parte desse debate se fez e se faz no largo de São Francisco. Por isso pode ser relevante ter consciência do que representa a escola, para o país, e pode representar para a vida, de cada um dos que tem a oportunidade e a responsabilidade de participar dela.

9 Em 2009, fiz a aula inaugural aqui nesta casa, com estudo retrospectivo e prospectivo, Direito Internacional nas Arcadas. Onde procurei resgatar parte desta nossa rica trajetória. Publicada na Revista da Faculdade de Direito da Universidade de São Paulo (2009). Na ocasião, lembrava existir acervo relevante de produção nacional em Direito Internacional a ser resgatado. Esse trabalho encontra-se em curso. De ponto de vista organizacional, tornou-se esta antiga cadeira todo um Departamento de Direito Internacional, e este tem caráter único, enquanto núcleo, institucionalmente organizado, de pesquisadores e docentes, no país, nas áreas do Direito Internacional Público, Direito Internacional Privado e Direito do Comércio Internacional. É preciso que se tenha consciência da importância desse conjunto, para que se pense e se opere como equipe, e não a mera somatória de projetos individuais paralelos.
} 
1. Fases da evolução do estudo e do ensino do Direito Internacional no Brasil, segundo V. M. Rangel

Cumpre ressaltar a necessidade da abrangência do enfoque e a pertinência da contextualização temporal e cultural, para o Direito Internacional, pelo caráter crucial de temas como a questão do uso da força, da construção dos princípios, da evolução da jurisprudência internacional, da codificação do Direito Internacional, e da consolidação das normas cogentes de Direito Internacional (jus cogens), bem como por situar a necessidade e o papel das instituições e do Direito Internacional, na ordenação das relações e da vida internacionais.

O Direito Internacional não pode ser visto nem tratado como disciplina puramente técnica: não tem caráter somente instrumental e não pode ser reduzido a isso. Tem dimensão intelectual e humana, a ser preservada, para que possa cumprir a sua missão precípua de construir bases para a comunicação e o diálogo entre os homens, como entre os colegiados humanos, sejam estes os estados, as organizações internacionais e os demais agentes do contexto internacional presente.

$\mathrm{O}$ estudo e o ensino do Direito das Gentes, à luz de fatos recentes e da evolução do sistema institucional e normativo internacional nos mostram o caráter empírico dessa tradição, e a pouca clareza que pode existir em relação a quais sejam as regras que orientam a prática corrente, quais linhas mestras podem ser apontadas, quais lições podem ser tiradas, não somente como reflexão sobre o passado, mas como referências presentes e parâmetros para orientar ação futura?

Conforme pondera V. Marotta Rangel: "Teria a análise do Direito das Gentes contemporâneo o efeito de prescindir da busca desse direito em tempos menos recentes?" Considera VMR autorizada a resposta negativa e nos faz reconhecer a presença dos ensinamentos de nosso predecessor na cadeira José Mendes - que a regeu de 1911 a 1918. "O contemporâneo surge aí como resumo e complemento das fases anteriores, a que os ensaios recorrem toda vez que se faça necessário compreender e vistoriar os quadrantes e o cerne do direito perquirido". ${ }^{10}$

“O direito está para o organismo social”, dizia José Mendes (1913), ${ }^{11}$ "como a veste para o organismo individual: um e outro acompanham o desenvolvimento do

10 RANGEL, Vicente Marotta. Introdução. In: TRINDADE, Antonio Augusto Cançado. Principios do direito internacional contemporâneo. Brasília: Ed. UnB, 1981.

11 MENDES, José. Direito internacional público: prelecções. São Paulo: Duprat \& Comp., 1913. ('prefácio', datado de 15 de novembro de 1913): "Este livro reflecte em synthese as minhas prelecções de direito internacional público, na Faculdade de Direito de São Paulo. / Transumpto da explicação de todas as theses de meu programma, traz a nomenclatura de todas as questões de mais destaque no assumpto, discutidas e resolvidas durante o curso. / Contém as linhas essenciaes dos institutos jurídico-mundiaes, sem descer a detalhes, consoante já aconselhavam os Estatutos da Universidade de Coimbra de 1772. / A linguagem é 
respectivo corpo. Cada fase da evolução social contém a fase anterior, com alguma coisa a mais. Cada fase é o resumo das fases anteriores, numa e noutra evolução", retomaria J. Mendes (1918). ${ }^{12}$ Foi graças a Marotta Rangel que descobri as lições de nosso predecessor na mesma insigne cátedra. Cátedra que José Mendes ocupou de 1911 a $1918 .{ }^{13}$

V. Marotta Rangel (1980) ${ }^{14}$ divide em quatro etapas o estudo e o ensino do Direito Internacional Público em nosso país, «que refletem, preponderantemente, eventos básicos de períodos históricos sucessivos».

Em verdade, a simples menção das balisas que marcam o início e o fim de cada etapa, nos sugere a profundidade das transformações por que tem passado as condições sociais e políticas da sociedade contemporânea, em que o direito internacional - como todo direito - se assenta.

1. Onde a primeira se projeta da independência até a conferência da paz, na Haia, em 1907: “o ensino do Direito das Gentes (segundo então era denominado) se iniciou com a instalação dos cursos jurídicos entre nós", com destaque para Lafayette Rodrigues Pereira e o Barão do Rio Branco. ${ }^{15}$

simples, conforme o salutar exemplo dos modernos expositores da matéria scientífica. Sciencia e rhetorica são coisas que se não attraem. ORNARI RES IPSA VETAT, CONTENTA DOCERI."

12 MENDES, José. Relação entre o direito internacional público e o direito nacional nos países americanos. Revista dos Tribunais, São Paulo, a. 6, v. 24, n. 130, p. 81-84, 1917.

13 CASELLA, P. B. Cem anos do direito internacional público (1913) de José MENDES (1861-1918) olhar reflexivo sobre o direito internacional nas Arcadas (1911-1918). Revista da Faculdade de Direito da Universidade de São Paulo, São Paulo, 2013, v. 108, p. 27-44, jan./dez. 2013.

14 RANGEL, Vicente Marotta. Introdução. In: TRINDADE, Antonio Augusto Cançado. Princípios do direito internacional contemporâneo. Brasília: Ed. UnB, 1981. p. v-xiv.

15 RANGEL, Vicente Marotta. Introdução. In: TRINDADE, Antonio Augusto Cançado. Princípios do direito internacional contemporâneo. Brasília: Ed. UnB, 1981. p. v-vi: "Os professores que primeiro lecionaram matérias próprias a esse direito na Academia de São Paulo foram Avelar Brotero e Amaral Gurgel que alternadamente o regiam. Coube àquele escrever a primeira obra de direito internacional público no Brasil: "Questões sobre presas marítimas", editada em 1836, em São Paulo, que surgiu, como se verifica, apenas quatro anos depois da edição dos "Princípios de derecho das gentes", da autoria de Andrés Bello, obra marcante na bibliografia latino-americana. Prioridade do ensino em Olinda coube a Lourenço José Ribeiro e Pedro Autran da Matta e Albuquerque. Deste último, que prelecionou em Pernambuco, por mais de cinco décadas, é a autoria dos "Elementos do direito das gentes segundo a doutrina dos escritores modernos", editado em 1851. Com o escopo de completá-lo e atualizá-lo subsequentemente, dois outros cursos se publicaram no Recife, também da lavra de docentes da mesma escola: as "Preleções de direito internacional", de Antonio de Vasconcellos Menezes de Drummond, e as "Lições elementares do direito das gentes", de João Silveira de Souza, datadas de 1867 e 1889, respectivamente. Foram também editados na segunda metade do século passado os "Elementos de direito internacional marítimo", de Carlos Vidal de Oliveira Freitas, e os "Apontamentos para o direito internacional, ou coleção completa dos tratados celebrados pelo Brasil", de Antonio Pereira Pinto, repositório, em quatro volumes, de documentos de relevância, nas relações exteriores de nosso país. Todas as publicações do século passado estão como que a preparar o advento da obra marcante do primeiro período, os "Princípios de direito internacional", de Lafayette Rodrigues Pereira, obra em dois tomos, publicada em 1902. Jurista de escol, no plano da teoria e da prática, avulta como se sabe, na última etapa do primeiro período, a prolongar-se no segundo, o Barão do Rio Branco." 
2. A segunda se intercala entre esta conferência da paz, em 1907, e a guerra de 1914-1918: a participação do Brasil na segunda conferência da Haia, "teve ampla repercussão entre nós e estimulou estudos em profundidade do Direito Internacional". ${ }^{16}$

3. A terceira se localiza entre os dois conflitos armados mundiais: "durante a terceira etapa se editaram exposições sistemáticas" V. Marotta Rangel (1980), ${ }^{17}$ durante a guerra o "o profundo estado de anormalidade refletiu-se como efeito adverso sobre a produção de Direito Internacional”, cf. tb. V. Marotta Rangel (1992). ${ }^{18}$

4. A quarta flui a partir da segunda guerra mundial: "desde o último conflito armado mundial, o Direito das Gentes, sem perder o sentido natural de continuidade no tempo e de sorte a refletir o rumo e o espírito das mudanças por que tem passado a comunidade internacional, ampliou extraordinariamente o seu âmbito de competência ratione materiae". ${ }^{19}$

16 RANGEL, Vicente Marotta. Introdução. In: TRINDADE, Antonio Augusto Cançado. Principios do direito internacional contemporâneo. Brasília: Ed. UnB, 1981. p. vi: "a começar pelos realizados pelo próprio chefe da delegação brasileira à Conferência, Ruy Barbosa, e continuados com os "Elementos de direito internacional", de autoria de Manuel Augusto de Sá Viana e a "Evolução do direito internacional", de João Cabral, que vieram à lume em 1908, no Rio de Janeiro. Em 1911 Epitácio Pessoa divulgou o seu "Projeto de código de direito internacional público", no Rio de Janeiro. Do mesmo ano e da mesma cidade é o "Direito internacional público" (com segunda edição em 1939) de Clóvis Bevilaqua." Dois pequenos reparos à observação: (i) a ênfase no 'direito público' primeiro e, depois, 'internacional', não é de pequena importância, em detrimento da dimensão internacional, com ênfase no direito público; (ii) a primeira edição (1910); BEVILAQUA, C. Direito público internacional: a synthese dos princípios e a contribuição do Brasil. 2. ed. Rio de Janeiro: Freitas Bastos, 1939 e . Direito público internacional: a synthese dos princípios e a contribuição do Brasil. Rio de Janeiro: Freitas Bastos, 1910.

17 RANGEL, Vicente Marotta. Introdução. In: TRINDADE, Antonio Augusto Cançado. Princípios do direito internacional contemporâneo. Brasília: Ed. UnB, 1981. p. vi: "como as de Raul Pederneiras, "Direito internacional compendiado" (1931) e de Braz de Souza Arruda, "Estrutura do direito internacional" (1938), sobressaindo-se o "Tratado de direito internacional público", em três tomos, de Hildebrando Accioly, editado entre 1933 e 1935 (com segunda edição em 1956). Em 1936 publicaram-se no Rio de Janeiro, "Gênese e evolução da neutralidade" e "Natureza jurídica do mar", de autoria, respectivamente de Linneu de Albuquerque Mello e Breno Machado Vieira Cavalcanti. Embora dedicando-se ao direito internacional privado, Haroldo Valladão analisou temas de internacional público, a que deu desenvolvimento na etapa ulterior."

18 RANGEL, Vicente Marotta. Public international law: the last five decades. In: DOLINGER, Jacob; ROSENN, Keith (Ed.). A panorama of Brazilian Law. Miami / Rio de Janeiro: Univ. of Miami North-South Center / Ed. Esplanada, 1992. p. 287-308. p. 290: "The profound abnormality of war period adversely affected the production of scholarly studies, even though the published lectures of Brás de Souza Arruda, entitled.

19 RANGEL, Vicente Marotta. Introdução. In: TRINDADE, Antonio Augusto Cançado. Princípios do direito internacional contemporâneo. Brasília: Ed. UnB, 1981. p. vii: "O desenvolvimento dos estudos do direito internacional público, em nosso país, tem estado a acompanhar-lhe as vicissitudes de transformação e relevância crescente, como atestam os trabalhos de docência, de pesquisa e de orientação conduzidos por eminentes juristas, que hoje o cultivam, com segurança e descortino, nas diversas cátedras e departamentos das universidades brasileiras, assim como na diplomacia." 
5. Desde 1945, o Direito Internacional, frisa V. Marotta Rangel (1980), ${ }^{20}$ "sofreu o impacto perturbador dos fatores econômicos, sociais, políticos e tecnológicos; acolheu novos sujeitos específicos, desde o ser humano, reidentificado à luz do Direito Positivo como pólo de irradiação e alvo de destino de todo ordenamento jurídico, até as organizações internacionais que, por seu turno, crescem, se diversificam e se reproduzem por si próprias; reavaliou as funções do estado, no contexto da sociedade global, embora sem desconhecer-lhe a presença e o prestígio de ator principal e indeclinável; acompanhou o relacionamento dos homens, em escala planetária e indagou, subseqüentemente, das condições dos cosmonautas e do regime jurídico dos corpos celestiais contactados; e voltou a perquirir dos valores fundamentais de convivência humana e de ordem jurídica respectiva."

O ensino do Direito Internacional, nos cursos jurídicos do Brasil, ${ }^{21}$ relegado à condição de disciplina 'optativa', no currículo mínimo dos cursos de Direito, ${ }^{22}$ durante a duvidosa "flexibilização", ocorrida no período de 1972 a 1994, ${ }^{23}$ e da qual ainda se notam os efeitos dessa escolha equivocada. ${ }^{24}$ Foram necessários mais de vinte anos, praticamente

20 RANGEL, Vicente Marotta. Introdução. In: TRINDADE, Antonio Augusto Cançado. Princípios do direito internacional contemporâneo. Brasília: Ed. UnB, 1981. p. vi.

21 RODRIGUES, Horácio Wanderlei. Novo currículo mínimo dos cursos jurídicos. São Paulo: Revista dos Tribunais, 1995; esp. cap. 1, 'ensino jurídico no Brasil: balanço geral', p. 9-39, contém breve relato histórico.

22 RODRIGUES, Horácio Wanderlei. Novo currículo mínimo dos cursos jurídicos. São Paulo: Revista dos Tribunais, 1995; cap. 2, 'o currículo e suas reformas, na história do ensino jurídico brasileiro', p. 40-61. Nos anos de 1972 a 1994, boa parte dos cursos de graduação em Direito, seguindo a diretriz da Resolução n. 3/72/CFE, de 25 de fevereiro de 1972, emanada do Conselho Federal de Educação, manteve o Direito Internacional Público ou Direito Internacional Privado, como duas escolhas possíveis, dentre leque das matérias optativas.

23 Se a ditadura de Vargas deixou marcas no país e no Direito Internacional entre nós, a ditadura militar também deixou. Ver a Resolução n. 3/72/CFE: O presidente do Conselho Federal de Educação, no uso de suas atribuições legais, na forma do art. 26, da Lei n. 5.540, de 28 de novembro de 1968, e tendo em vista o parecer 162/72 (...) resolve: art. $1^{\circ}$. O currículo mínimo do curso de graduação em Direito compreenderá as seguintes matérias: (...) 1 a 11 (...) 12/13. "Duas dentre as seguintes: (a) direito internacional público, (b) direito internacional privado, (c) ciência das finanças e direito financeiro (tributário e fiscal), (d) direito da navegação (marítima), (e) direito romano, (f) direito agrário, (g) direito previdenciário, (h) medicina legal, de elenco compreendendo, ainda, a exigência de "prática forense, sob a forma de estágio supervisionado" e "o estudo de problemas brasileiros e a prática de educação física, com predominância desportiva, de acordo com a legislação específica" etc.”.

24 Até ser substituída por Portaria, com o regime aplicável, a partir de 1994, quando retorna à obrigatoriedade o ensino do Direito Internacional nos cursos jurídicos nacionais. Cf. Portaria n. 1.886/94/MEC, art. 6”: "O conteúdo mínimo do curso jurídico, além do estágio, compreenderá as seguintes matérias, que podem estar contidas em uma ou mais disciplinas do currículo pleno de cada curso. I - fundamentais: introdução ao direito; filosofia (geral e jurídica); ética geral e profissional; sociologia (geral e jurídica); economia e ciência política (com teoria geral do estado); II - profissionalizantes: direito constitucional, direito civil, direito administrativo, direito tributário, direito penal, direito processual civil direito processual penal, direito do trabalho, direito comercial e direito internacional. Parágrafo único: as demais matérias e novos direitos 
o espaço de vida útil de uma geração, ${ }^{25}$ para voltar o Direito Internacional a ser parte do currículo mínimo 'obrigatório', ${ }^{26}$ em muitas faculdades deste nosso vasto Brasil.

Consigne-se nunca se ter interrompido o ensino do Direito Internacional nesta casa. Fazia questão de frisar Geraldo Eulálio do Nascimento e Silva (1917-2003), ter sido graças ao empenho de V. Marotta Rangel, durante os quase trinta anos em que regeu esta cátedra, de 1966 até 1994, nunca se ter deixado de ensinar Direito Internacional nas Arcadas! $!^{27}$

Considerar o Direito Internacional à luz do contexto pós-moderno significa inovar, no enfoque dado ao conjunto dos temas centrais da disciplina, contextualizado no mundo atual, ante a necessidade de responder ao desafio, que se põe para o Direito como um todo, e se analisa em relação ao Direito Internacional. A pós-modernidade enfatiza a necessidade dos princípios, normas e procedimentos de Direito Internacional, não somente como ferramentas da paz e da segurança internacionais, mas como condições para a sobrevivência da humanidade, em mundo no qual a capacidade tecnológica de causar a destruição da vida e da civilização no planeta desenvolveu-se muito mais do que os mecanismos institucionais para garantir a paz: o quadro apresenta riscos e as ameaças são presentes e relevantes, mas a convicção da possibilidade de aperfeiçoamento das instituições e das normas internacionalmente indispensáveis. Este é o modo melhor e mais seguro de garantir os fundamentos e o desenvolvimento do Direito Internacional - para esta e as próximas gerações.

Essa lição sobre a continuidade e o encadeamento histórico e temático no Direito Internacional pós-moderno tem sido aplicada, e dela tem resultado linha

serão incluídos nas disciplinas em que se desdobrar o currículo pleno de cada curso, de acordo com suas peculiaridades e com observância de interdisciplinaridade."

25 Finalmente, descobriram os burocratas universitários a importância deste? E a falta que faz o Direito Internacional, para a formação do bacharel em Direito, no mundo globalizado? Ver RODRIGUES, Horácio Wanderlei. Novo currículo mínimo dos cursos jurídicos. São Paulo: Revista dos Tribunais, 1995; cap. 3, 'a Portaria n. 1.886/94/MEC e o novo currículo mínimo dos cursos jurídicos', p. 62-93.

26 O estudo e o ensino do Direito, no globalizado e conturbado mundo pós-moderno não pode prescindir da formação em Direito Internacional: parecem ter se dado conta disso - e essa necessidade se faz sentir junto ao mercado e pelo mercado, com a mudança considerável da percepção da necessidade e do papel das disciplinas do Direito Internacional, se considerarmos período histórico relativamente curto, como os últimos vinte e cinco anos: de interesse minoritário, como historicamente se manteve, passa a ter procura ampliada e suscitar interesse renovado, junto aos estudantes. É fundamental que essas possíveis vocações sejam, primeiro, bem formadas e, a seguir, bem orientadas.

27 Em razão da amplitude crescente como das dificuldades dos temas contidos em nossas disciplinas deu-se a progressiva institucionalização, no seio do que vem a ser, desde o início dos anos setenta, o Departamento de Direito Internacional (DIN) da FDUSP, para preparar e adotar, em duas cadeiras que se somam à original, de direito internacional público, destinadas ao ensino do Direito Internacional Privado e do Direito do Comércio Internacional, o conjunto das matérias que passam a compor o ensinamento de nosso departamento. Assim se mostra a percepção da necessidade do assunto, apesar das dificuldades, politicamente inerentes a seu tratamento jurídico, bem como a utilidade possível de estabelecer tais normas e quadros institucionais internacionais. 
importante de trabalho sobre a evolução institucional do Direito Internacional no tempo. ${ }^{28}$ Destacar um momento fará perder a compreensão do todo - sobretudo, quando se trata do "Direito das Gentes".

\section{Princípios constitucionais do Direito Internacional na obra de V. Marotta Rangel}

Considerando a configuração de determinado sistema nacional de Direito Internacional Público, V. Marotta Rangel (1992) ${ }^{29}$ aponta a necessidade de o considerar na dimensão do Direito Internacional Constitucional, o que traz a inter-relação entre as normas hierarquicamente superiores do sistema jurídico interno, para a análise dessa matéria, o que permite mostrar a evolução do tratamento do Direito Internacional, pelo sistema jurídico interno.

Para tanto, VMR divide em cinco períodos, relacionados a mudanças constitucionais, para aferição da evolução do Direito Internacional no Brasil, a partir de 1940, até o presente: onde o período de anormalidade (1940-1946), característica desse tempo, igualmente nos planos interno e internacional: ${ }^{30}$ no plano interno, em razão da Constituição de 10 de novembro de 1937, em vigor no período, não somente manchada por vícios de origem, ${ }^{31}$ mas igualmente em sua aplicação; a anormalidade no plano internacional, devia-se à ocorrência da segunda guerra mundial.

28 CASELlA, P. B. Direito internacional no tempo moderno de Suarez a Grócio. São Paulo: Atlas, 2014 (ISBN 9788522482870); CASELLA, P. B. Direito internacional no tempo medieval e moderno até Vitória. São Paulo: Atlas, 2012. (ISBN 9788522473120); CASELLA, P. B. Direito internacional no tempo antigo. São Paulo: Atlas, 2012. (ISBN 9788522462957); CASELLA, P. B. Direito internacional dos espaços. São Paulo: Atlas, 2009. (ISBN 9788522456253); CASELLA, P. B. Fundamentos do direito internacional pósmoderno. Prólogo Hugo Caminos. São Paulo: Quartier Latin, 2008. (ISBN 9788576743361).

29 RANGEL, Vicente Marotta. Public international law: the last five decades. In: DOLINGER, Jacob; ROSENN, Keith (Ed.). A panorama of Brazilian Law. Miami / Rio de Janeiro: Univ. of Miami North-South Center / Ed. Esplanada, 1992. p. 287-308.

30 RANGEL, Vicente Marotta. Public international law: the last five decades. In: DOLINGER, Jacob; ROSENN, Keith (Ed.). A panorama of Brazilian Law. Miami / Rio de Janeiro: Univ. of Miami North-South Center / Ed. Esplanada, 1992. p. 287-308. (item i 'period of abnormality (1940-1946)', p. 287-290).

31 RANGEL, Vicente Marotta. Public international law: the last five decades. In: DOLINGER, Jacob; ROSENN, Keith (Ed.). A panorama of Brazilian Law. Miami / Rio de Janeiro: Univ. of Miami NorthSouth Center / Ed. Esplanada, 1992. p. 287-308: "The autocratically inspired Constitution of 1937 was promulgated by President Getúlio Vargas under the allegation, among others, of a 'state of apprehension created in the country by Communist infiltration' [Const. of 1937, second Whereas of the Preamble]. The Constitution dissolved the Chamber of Deputies and the Senate [id., art. 178], providing that elections were to be held after a plebiscite on the Constitution [id., arts. 185 and 187]. This plebiscite was never held. While Congress was suspended, the President of the Republic had 'the power to issue decree-laws on all matters within the legislative competence of the Federal government' [id., art. 180]. For almost an entire decade, the President exercised this power using it as a basis for making important decisions in the areas of both domestic and foreign policy." 
Avalia VMR: mantendo a tradição de Constituições anteriores, a Constituição de 1937 continha disposições a respeito de Direito Internacional. Esta, contudo, diferia das anteriores em pontos sintomaticamente relevantes: primeiro não previa tentativa de solução amigável, por meio de arbitragem, antes de declaração de guerra, e deixava de condenar qualquer guerra de conquista; em segundo lugar, impunha aos estados a obrigação de "promover, no âmbito de suas respectivas esferas de competência, as medidas necessárias à execução de tratados de comércio, celebrados pelo governo federal", nos termos do art. 10 .

O governo brasileiro também participou de outra ação mostrando frente unida, no continente: a ruptura de relações diplomáticas com o Japão, a Alemanha e a Itália. ${ }^{32}$ Em 6 e 8 de fevereiro de 1943, o Brasil assinou, respectivamente, a Carta atlântica e a Declaração das Nações Unidas. Como observa Hélio Vianna (1958): “a neutralidade do Brasil foi sempre exemplar, mas nossa solidariedade com a América é histórica e tradicional", ${ }^{33}$

Em 1944, a Força expedicionária brasileira e o Primeiro grupo de combate aéreo travaram combate na Europa, sob o comando do general João Batista Mascarenhas de Moraes, até maio de 1945. O governo brasileiro, gradualmente, começou a participar de ações conjuntas de interesse dos países, engajados na luta contra o Eixo. Em 9 de

32 RANGEL, Vicente Marotta. Public international law: the last five decades. In: DOLINGER, Jacob; ROSENN, Keith (Ed.). A panorama of Brazilian Law. Miami / Rio de Janeiro: Univ. of Miami North-South Center / Ed. Esplanada, 1992. p. 287-308: According to a note dated 28 January 1942, in accordance with the resolution of the Third meeting of the foreign ministers of the American republics adopted that same day, the rupture was caused by the fact that 'the first of those countries has committed aggression against, and the latter two have declared war upon, an American state'. The sinking of five Brazilian ships transporting passengers (military and civilian) and merchandise in coastal trading, resulted in a note from the government at Rio de Janeiro on 21 August 1942, directed to Germany and to Italy, in which it recognized that a state of belligerence had been created between Brazil and those two countries. Decree no. 10,358 of 31 August 1942 declared a state of war throughout Brazil.

33 VIANNA, Hélio. História diplomática do Brasil. São Paulo: Melhoramentos, 1958; cap. xxv, 'o Brasil na segunda guerra mundial', p. 195-202, cit. p. 200, e a seguir, p. 202: "Como sinal de solidariedade continental, o Brasil também declarou guerra ao Japão, não tendo chegado a entrar em campanha contra esse país pela sua antecipada derrota, no mesmo ano de 1945"; RANGEL, Vicente Marotta. Public international law: the last five decades. In: DOLINGER, Jacob; ROSENN, Keith (Ed.). A panorama of Brazilian Law. Miami / Rio de Janeiro: Univ. of Miami North-South Center / Ed. Esplanada, 1992. p. 287-308. p. 290: "In 1943, two monographs on international law were published in Rio de Janeiro: "Gênese e evolução da neutralidade" by Linneu de Albuquerque Mello and "Natureza jurídica do mar" by Breno Machado Vieira Cavalcanti. In that same year, "Um conceito de guerra no direito internacional" by Mario Pessoa, was published in Recife. Two years later, Jorge Americano published "O novo fundamento do direito internacional e o seu esteio na consciência universal" (São Paulo: Ed. Renascença). / An auspicious event during this period was the launching of the Boletim da sociedade brasileira de direito internacional, whose first number covered the first six months of 1945. This publication, now called the Boletim brasileiro de direito internacional, is the most complete repository in Brazil of scholarship relating to the law of nations." 
novembro de 1943, o Brasil assinou a Convenção das Nações Unidas para a administração de assistência e reabilitação. ${ }^{34}$

O Brasil ratificou as Convenções para a criação do Fundo Monetário Internacional e do Fundo para a reconstrução e o desenvolvimento, assinadas em Bretton Woods, em 22 de julho de 1944. Pela sua participação na guerra, o Brasil preencheu as condições para participar da Conferência das Nações Unidas, em San Francisco, sendo signatário da Carta das Nações Unidas, em 26 de junho de 1945. Desde então, tem sido participante ativo da ONU, e das suas organizações especializadas.

A continuação do conflito no Pacífico explica o Decreto n. 18.811 de 6 de junho de 1945, que declarava estado de guerra entre o Brasil e o Japão. Após a cessação de todo conflito armado, o governo brasileiro publica o Decreto n. 19.955 de 16 de novembro de 1945, suspendendo o estado de guerra, que persistira por mais de três anos.

A tanto se seguiria o "retorno à normalidade" (1946-1964). ${ }^{35}$ Com o fim da segunda guerra mundial e o subsequente triunfo dos princípios contidos na Carta das Nações Unidas profunda reformulação das insuportáveis condições políticas, estipuladas pela Constituição de 1937, tornaram-se inevitáveis. A ditadura de Getúlio Vargas foi derrubada e nova Constituição democrática foi promulgada em 18 de setembro de 1946, marcando o retorno à normalidade institucional!

Dentre os dispositivos da Constituição de 1946, com relevância para o Direito Internacional, o artigo quarto, que tivera como inspiração a Constituição francesa de 1791, e como fontes mais próximas as Constituições brasileiras de 1891 e de 1934 , mas vira-se eliminado da Constituição de 1937, estipulava que o Brasil não recorreria a guerra exceto se "recurso a arbitragem ou meios pacíficos de solução de controvérsias regulados por órgão internacional de segurança" do qual fosse membro o Brasil, não estivesse disponível ou não tivesse alcançado resultado; além disso, em hipótese alguma o Brasil recorreria a guerra de conquista, direta ou indireta, atuando por conta própria ou por meio de aliança, com outro estado, tendo a redação desse dispositivo sido aperfeiçoada em constituições posteriores. ${ }^{36}$

A respeito dessa fase de 1946 até 1964, observa VMR que na Carta constitucional de 1946, os poderes do presidente da República seguiam, em linhas gerais,

34 United Nations Convention relief and rehabilitation administration (UNRRA), de 9 de novembro de 1943; promulgada pelo Decreto n. 16.718 de 3 de outubro de 1944.

35 RANGEL, Vicente Marotta. Public international law: the last five decades. In: DOLINGER, Jacob; ROSENN, Keith (Ed.). A panorama of Brazilian Law. Miami / Rio de Janeiro: Univ. of Miami North-South Center / Ed. Esplanada, 1992. p. 287-308. (item ii, 'return to normality (1946-1964)', p. 290-294).

36 RANGEL, Vicente Marotta. Public international law: the last five decades. In: DOLINGER, Jacob; ROSENN, Keith (Ed.). A panorama of Brazilian Law. Miami / Rio de Janeiro: Univ. of Miami NorthSouth Center / Ed. Esplanada, 1992. p. 287-308. p. 291: "The wording of this provision was improved in subsequent constitutions." 
aqueles estipulados na Constituição de 1937. Também se mantiveram dispositivos, anteriormente adotados, relativos aos poderes do presidente da República e do Congresso, com relação ao poder de celebrar tratados e ao poder de declarar guerra e celebrar a paz. ${ }^{37}$ Dentre os poderes exclusivos do Senado, não contemplados no texto de 1937, estava o da aprovação, mediante voto secreto, dos chefes de missões diplomáticas permanentes, bem como da autorização para a contratação de empréstimos externos, pelos estados, o distrito federal e os municípios.

Observa VMR que na Carta de 1946, os poderes do Supremo Tribunal Federal foram preservados, com algumas inovações: o art. 101 (i) d, agora corretamente mencionava 'estados' e não mais 'nações', e o mesmo dispositivo ampliava a esfera jurisdicional do STF, conferindo a este a jurisdição originária não somente sobre casos entre estados estrangeiros e o Governo Federal ou Governos Estaduais, mas igualmente em relação a casos entre estados estrangeiros e o Distrito Federal ou municípios.

Diversas importantes convenções em matéria de Direitos Humanos foram aprovadas. ${ }^{38}$ Ao mesmo tempo, o Brasil declarava ser a plataforma continental "parte integrante do território nacional" e aderia ao Acordo de Washington sobre a pesca da baleia (1946). ${ }^{39}$

O impacto das transformações em curso no mundo influencia a produção a respeito do Direito Internacional na época. ${ }^{40}$ Quando dedica V. Marotta Rangel a sua tese

37 RANGEL, Vicente Marotta. Public international law: the last five decades. In: DOLINGER, Jacob; ROSENN, Keith (Ed.). A panorama of Brazilian Law. Miami / Rio de Janeiro: Univ. of Miami North-South Center / Ed. Esplanada, 1992. p. 287-308: "In the two decades during which the 1946 Constitution was in force, appreciable changes occurred in international relations that had immediate repercussions upon the Brazilian legal order. When the Second World War ended, Brazil adhered to the peace treaties celebrated at that time. Brazil approved the treaties celebrated in Paris on 10 February 1948, with Italy and in San Francisco on 8 September 1951, with Japan." -- surpreendentemente, mais de sessenta anos transcorridos desde o fim da segunda guerra mundial e, todavia, existem ativos expropriados dos então inimigos de guerra, transferidos pela União ao exército brasileiro, e até hoje não devolvidos nem ressarcidos!

38 A Convenção sobre o status dos refugiados, ratificada em 15 de novembro de 1960, com reservas aos arts. 15 e 17 e a opção com relação aos dispositivos da Seção B.1 do art. $1^{\circ}$ da Convenção (Dec. n. 50.215, de 28 jan. 1961); a Convenção sobre Direitos Políticos das Mulheres, assinada em Nova York, em 1963 (Dec. n. 53.476, de 17 set. 1963); a Convenção 95 da OIT sobre a proteção salarial (1949) (Dec. n. 41.721, 25 jun. 1957); a Convenção 98 da OIT sobre direitos de organização e negociação coletiva (1949) (Dec. n. 33.196, de 29 jun. 1953).

39 Dec. n. 28.840 de 8 nov. 1950; Agreement on the regulation of whaling, assinado em Washington, em 2 dez. 1946 (Dec. n. 28.524, de 18 ago. 1950).

40 RANGEL, Vicente Marotta. Public international law: the last five decades. In: DOLINGER, Jacob; ROSENN, Keith (Ed.). A panorama of Brazilian Law. Miami / Rio de Janeiro: Univ. of Miami North-South Center / Ed. Esplanada, 1992. p. 287-308. (p. 293-294) cita como destaques da época: (PESSOA, Mário. O direito internacional moderno. Rio de Janeiro: Freitas Bastos, 1947); (FARO JUNIOR, Luiz. Manual de direito internacional público. Rio de Janeiro: Livraria Martins, 1951); (ACCIOLY, Hildebrando. Manual de direito internacional público. São Paulo: Saraiva, 1957); in 1956, Accioly also published the second edition of his three volume, "Tratado de direito internacional" (...) "worthy of note was the course offered in 1959 at the Academy of International Law in the Hague by Hildebrando Accioly on general principles 
de livre-docência ao exame dos "conflitos entre a Carta das Nações Unidas e os demais acordos internacionais" (1954). ${ }^{41}$ A questão dos Direitos Humanos impõe-se como tópico de estudo no contexto do Direito Internacional. ${ }^{42}$ José Sette Câmara publica, no Canadá, o estudo a respeito da "ratificação dos tratados" (1949), ${ }^{43}$ Rubens Ferreira de Mello publica o "Tratado de Direito Diplomático" (1948) e o "Dicionário de Direito Internacional Público» (1946), ${ }^{44}$ enquanto João Hermes Pereira de Araújo publica seu estudo a respeito da "processualística dos atos internacionais no Brasil" (1958). ${ }^{45}$

Apesar do quadro de exceção, existente em razão da ditadura militar, a partir de 1964, vários atos internacionais foram assinados e ratificados. Dentre os de vocação universal, ${ }^{46}$ com destaque para a Convenção de Viena sobre relações diplomáticas

of international liability": ACCIOLY, Hildebrando. Principes généraux de la responsabilité internationale d'après la doctrine et la jurisprudence. Recueil des Cours, v. 96, p. 349-442, 1959; LUZ, Nelson Ferreira da. Introdução ao direito internacional público. São Paulo: Saraiva, 1963; ARRUDA, Brás de Souza. Estrutura do direito internacional. Revista da Faculdade de Direito da Universidade de São Paulo, São Paulo, v. 58, p. 32-92, 1963; "this author had earlier published his" Curso de direito internacional: na era atômica. Curitiba: Guaíra ed., 1920; Gilda Russomano "collected several of her writings in" (RUSSOMANO, Gilda. Estudos de direito internacional. Rio de Janeiro: José Konfino, 1956); MARINHO, Ilmar Penna. Características essenciais do novo direito internacional. Rio de Janeiro: Imprenta Nacional, 1947; MARINHO, Ilmar Penna. Tratado sobre a nacionalidade. Rio de Janeiro: Imprensa nacional, 1956; VALLADÃO, Haroldo. Democratização e socialização do direito internacional. Rio de Janeiro: José Olympio, 1961.

41 RANGEL, Vicente Marotta. Do conflito entre a Carta das Nações Unidas e os demais acordos internacionais. 1954. (Tese de Livre-Docência) - Faculdade de Direito, Universidade de São Paulo, São Paulo, 1954.

42 SODER, José. Direitos do homem. São Paulo: Nacional, 1960; BOSON, Gerson de Brito Mello. O homem como sujeito de direito internacional. Belo Horizonte: [s.n.], 1951; BOSON, Gerson de Brito Mello. Curso de direito internacional público. Belo Horizonte: B. Álvares, 1958; nova edição: BOSON, Gerson de Brito Mello. Direito internacional público: o estado em direito das gentes. Belo Horizonte: Del Rey, 1994.

43 CÂMARA, José Sette. The ratification of international treaties. Toronto: The Ontario publishing company, 1949.

44 MELLO, Rubens Ferreira de. Tratado de direito diplomático. Rio de Janeiro: Ed. Clássica Livraria, 1948; MELLO, Rubens Ferreira de. Dicionário de direito internacional público. Rio de Janeiro: [s.n.], 1946.

45 ARAÚJO, João Hermes Pereira de. A processualistica dos atos internacionais no Brasil. Rio de Janeiro: MRE, 1958; a respeito do mesmo tema, relevante a contribuição de MERCADANTE, Araminta de Azevedo. Processualística dos atos internacionais: Constituição de 1988 e MERCOSUL. In: CASELLA, P. B. et al. (Coord.). Contratos internacionais e direito econômico no MERCOSUL: após o término do período de transição. São Paulo: LTr, 1996. p. 458-505.

46 RANGEL, Vicente Marotta. Public international law: the last five decades. In: DOLINGER, Jacob; ROSENN, Keith (Ed.). A panorama of Brazilian Law. Miami / Rio de Janeiro: Univ. of Miami North-South Center / Ed. Esplanada, 1992. p. 287-308. p. 295: "Among the international acts that came into effect in this period, one should mention the Rules and recommendations appearing in Exhibit 9 to the Convention on International Civil Aviation ( $5^{\text {th }}$ edition), which provided for the facilitation of carriage by air [Dec. n. 54.203, de 24 ago. 1964], the Single convention on narcotic drugs [Dec. n. 54.216, de 27 ago. 1964], the Convention concerning the international exchange of publications, adopted by the UNESCO General conference at Paris on 3 December 1958 [Dec. n. 54.291, de 16 set. 1964]". 
(1961), ${ }^{47}$ também no contexto interamericano. ${ }^{48}$ Em matéria de direitos humanos, o Brasil adere à Convenção sobre escravidão, assinada em Genebra, em 25 de setembro de 1926, com as alterações resultantes do Protocolo e aberta para assinatura em Nova York, em 7 de dezembro de 1953, bem como a Convenção suplementar sobre a abolição da escravatura, do tráfico de escravos, e de instituições e práticas equivalentes à escravidão, adotada em Genebra, em 7 de setembro de $1956 .{ }^{49}$ Várias Convenções emanadas da O.I.T., em matéria trabalhista, foram incorporadas ao ordenamento jurídico brasileiro. ${ }^{50}$

Dentre doutrina de Direito Internacional, no período, apesar do que VMR chamou de "progressivo adensamento do negro quadro interno", são publicados relevantes estudos sobre Direitos Humanos, ${ }^{51}$ sobre proscrição de armas nucleares, ${ }^{52}$ sobre espaço exterior e responsabilidade internacional, ${ }^{53}$ sobre Direito Diplomático, ${ }^{54}$ sobre tratados ${ }^{55} \mathrm{e}$ sobre o Direito da Guerra. ${ }^{56}$

A Conferência das Nações Unidas sobre o Direito do Mar ensejou, entre nós, a publicação da tese de titularidade em Direito Internacional de V. Marotta Rangel, a respeito da "natureza jurídica e delimitação do mar territorial" (1966) ${ }^{57}$ e de dois livros

47 Convenção de Viena sobre relações diplomáticas, assinada a 18 de abril de 1961, entrada em vigor a 24 de abril de 1964; aprovada pelo Dec.-leg. n. 1.003, de 1964; ratificada a 23 de fevereiro de 1965, com depósito do instrumento de ratificação a 25 de março de 1965, tendo entrado em vigor, para o Brasil, a 4 de abril do mesmo ano; promulgada, no Brasil, pelo Dec. n. 56.435, de 8 de junho de 1965 (DOU de 11 de junho de 1965).

48 RANGEL, Vicente Marotta. Public international law: the last five decades. In: DOLINGER, Jacob; ROSENN, Keith (Ed.). A panorama of Brazilian Law. Miami / Rio de Janeiro: Univ. of Miami North-South Center / Ed. Esplanada, 1992. p. 287-308: "the Accord on the privileges and immunities of LAFTA [Dec. n. 57.784, de 11 fev. 1966], the Treaty banning nuclear weapons tests in the atmosphere, in outer space and under water [Dec. n. 58.256, de 26 abr. 1966], and the Basic agreement on technical assistance with the U.N., its specialized agencies and the International Atomic Energy Agency [Dec. n. 59.298, de 23 abr. 1966]. / In the Inter-american field, one should mention the Caracas Conventions on diplomatic asylum and territorial asylum, both dated 28 March 1954 [Dec. n. 55.929, de 14 abr. 1965], and the American treaty on peaceful solutions, the Bogotá Pact, dated 30 April 1948 [Dec. n. 57.785, de 11 fev. 1966]".

49 Convenção sobre escravidão, Genebra, 25 set. 1926, com alts. resultantes do Protocolo de Nova York, 7 dez. 1953; Convenção suplementar sobre a abolição da escravatura, do tráfico de escravos, e de instituições e práticas equivalentes à escravidão, Genebra, 7 set. 1956, promulgação pelo Dec. n. 58.563, de $1^{\circ}$ jun. 1966.

50 Convenções da O.I.T.: n. 22, n. 97, n. 103, n. 104, n. 105, n. 106, n. 107, n. 108, n. 110, n. 113; promulgadas em 14 jul. 1966, pelos Decretos ns. 58.817 até 58.827.

51 DUNSHEE DE ABRANCHES, C. A. Proteção internacional dos direitos humanos. Rio de Janeiro: Freitas Bastos, 1964.

52 DUNSHEE DE ABRANCHES, C. A. Proscrição das armas nucleares. Rio de Janeiro: Freitas Bastos, 1964.

53 DUNSHEE DE ABRANCHES, C. A. Espaço exterior e responsabilidade internacional. Rio de Janeiro: Freitas Bastos, 1964.

54 FRANCHINI NETTO, M. Diplomacia: instrumento da ordem internacional. Rio de Janeiro: Freitas Bastos, 1964.

55 MELLO, Celso D. de Albuquerque. Ratificação de tratados. Rio de Janeiro: Freitas Bastos, 1966.

56 MATTOS, José Dalmo F. Belfort de. Conceito cristão de guerra. São Paulo: Revista dos Tribunais, 1964. (PUC, tese de titularidade em Direito Internacional).

57 RANGEL, Vicente Marotta. Natureza jurídica e delimitação do mar territorial. 2. ed. rev. São Paulo: 
de Celso D. de Albuquerque Mello, sobre "plataforma continental" (1965) e "mar territorial" (1965). ${ }^{59}$

No seu estudo sobre "cinco décadas de Direito Internacional no Brasil" Marotta Rangel chamou esse período de "tendência ditatorial" (1967-1988). ${ }^{60}$

Nos termos do Ato Institucional n. 4 de 7 de dezembro de 1966, o Congresso nacional reuniu-se em sessão extraordinária, em 12 de dezembro do mesmo ano, e em 24 de janeiro do ano seguinte, para discutir, votar e promulgar o Anteprojeto de constituição submetido pelo presidente da república, que se tornaria a Constituição, de 24 de janeiro de 1967, por sua vez revogada pela Emenda Constitucional n. 1, de 17 de outubro de $1969 .{ }^{61}$

Alterou-se a disposição antes contida no art. $4^{\circ}$, da Constituição de 1946, passando o art. $7^{\circ}$ a estipular, de modo tecnicamente mais preciso, que conflitos internacionais seriam solucionados "mediante negociações diretas, arbitragem e outros meios pacíficos de solução de controvérsias", com a cooperação de organizações internacionais das quais o Brasil seja membro. O parágrafo único desse mesmo art. $7^{\circ}$ proibia "guerra de conquista".

Não foram feitas modificações substanciais aos poderes do executivo e do legislativo. ${ }^{62}$ A redação da Constituição de 1946 foi mantida em relação à aprovação

Revista dos Tribunais, 1970; RANGEL, Vicente Marotta. Le plateau continental dans la Convention de 1982 sur le droit de la mer. Recueil de Cours, v. 5, n. 194, p. 269-428, 1985.

58 MELLO, Celso D. de Albuquerque. Plataforma continental. Rio de Janeiro: Freitas Bastos, 1965; RANGEL, Vicente Marotta. Public international law: the last five decades. In: DOLINGER, Jacob; ROSENN, Keith (Ed.). A panorama of Brazilian Law. Miami / Rio de Janeiro: Univ. of Miami North-South Center / Ed. Esplanada, 1992. p. 287-308. p. 296; menciona: "1966" como ano de publicação deste livro de C. D. A. Mello.

59 MELLO, Celso D. de Albuquerque. Mar territorial. Rio de Janeiro: Freitas Bastos, 1965.

60 RANGEL, Vicente Marotta. Public international law: the last five decades. In: DOLINGER, Jacob; ROSENN, Keith (Ed.). A panorama of Brazilian Law. Miami / Rio de Janeiro: Univ. of Miami North-South Center / Ed. Esplanada, 1992. p. 287-308. (item iv, 'autocratic tendency (1967-1988)', p. 296-305).

${ }^{61}$ RANGEL, Vicente Marotta. Public international law: the last five decades. In: DOLINGER, Jacob; ROSENN, Keith (Ed.). A panorama of Brazilian Law. Miami / Rio de Janeiro: Univ. of Miami North-South Center / Ed. Esplanada, 1992. p. 287-308. (item cit. p. 296-297): "Although both Constitutions reflected the autocratic tendency prevailing during that period, they retained provisions of international interest, integrating prior Constitutions", onde cumpre, ademais, notar "the 1969 changes did not directly affect provisions related to international law".

62 RANGEL, Vicente Marotta. Public international law: the last five decades. In: DOLINGER, Jacob; ROSENN, Keith (Ed.). A panorama of Brazilian Law. Miami / Rio de Janeiro: Univ. of Miami North-South Center / Ed. Esplanada, 1992. p. 287-308: "with the exception of adding the term 'international acts' after the traditional phrase 'international treaties and conventions'. Thus, the 1967 Constitution gave exclusive power to the National Congress to make definitive resolutions on international treaties, conventions and acts celebrated by the President of the Republic" [Const. 1967, art. 47 (i)]. It gave exclusive power to the President of the Republic to 'celebrate international treaties, conventions and acts, ad referendum the National Congress' [id., art. 83 (viii)]. 
pelo Senado dos chefes de missão e modificada em relação a empréstimos externos, com poderes ampliados, para abranger "transações ou acordos internacionais", ${ }^{63}$

A jurisdição originária do Supremo Tribunal Federal foi mantida, na Constituição de 1967, quanto a julgar pedidos de extradição e a homologar sentenças estrangeiras, mantendo-se a previsão de atuação deste, em grau de apelação, quando se tratasse de decisão de tribunal inferior, recusando efeito a tratado ou declarando inconstitucional qualquer tratado, com algumas modificações: a jurisdição originária do STF passou a abranger casos nos quais fossem parte organizações internacionais ou territórios; foram desta excluídos casos nos quais municípios fossem parte.

Durante esse período manteve-se o ritmo de incorporação de acordos internacionais ao sistema jurídico interno brasileiro, como dão testemunho: a Organização hidrográfica internacional, conforme tratado assinado em Mônaco, em 3 de maio de $1967,{ }^{64}$ a Organização mundial da propriedade intelectual, conforme tratado assinado em Estocolmo, em 14 de julho de 1967, ${ }^{65}$ a Convenção do Instituto Internacional do Algodão, conforme tratado aberto para assinaturas em Washington, em 17 de janeiro de 1966, ${ }^{66}$ a INTELSAT, conforme tratado assinado em Washington, em 20 de agosto de 1971, ${ }^{67}$ a INMARSAT, conforme tratado celebrado em Londres, em 7 de setembro de 1967, e seu respectivo Protocolo, ${ }^{68}$ a Organização das Nações Unidas para o desenvolvimento industrial (UNIDO), conforme tratado celebrado em Viena, em 8 de abril de 1979. ${ }^{69}$

Diversos atos governamentais relativos a organizações internacionais foram adotados, como, por exemplo, as sanções políticas e econômicas contra a Rodésia do Sul, em conformidade com os termos da Resolução do Conselho de Segurança da ONU 232 (1966) e 253 (1968), bem como o Dec. n. 91.524, de 9 de agosto de 1985, regulando restrições às relações com a África do Sul, em razão das Resoluções do Conselho de Segurança 473 (1980), 588 (1984), 566 (1985) e 569 (1985). Além disso, o Brasil aprovou acordo com o Fundo das Nações Unidas para a Infância, assinado em Nova York, em 28 de março de $1966 .^{70}$

No plano das organizações internacionais regionais, pode ser lembrado o Protocolo de Buenos Aires, assinado em 27 de fevereiro de 1967, relativo à reforma da

\footnotetext{
63 A EC de 1969 acrescentou "that in case of foreign loans, transactions or agreements, "the federal executive branch should be consulted'."

64 International hydrographic organization; cf. Dec. n. 68.106, de 25 jan. 1971.

65 World intellectual property organization; cf. Dec. n. 75.541, de 31 mar. 1975.

66 International Cotton Institute Convention; cf. Dec. n. 70.060, de 18 fev. 1972.

67 International telecommunications satellite organization; aprovado pelo Dec.-leg. n. 87, de 5 dez. 1972.

68 International maritime satellite telecommunications organization; cf. Dec. n. 83.976, de 17 set. 1979.

69 United Nations industrial development organization; aprovado pelo Dec.-leg. n. 109, de 4 nov. 1980.

70 United Nations Children's Fund; cf. Dec. n. 62.125, de 16 jan. 1968.
} 
Organização dos Estados Americanos, ${ }^{71}$ bem como a Carta da Organização dos Estados Americanos, conforme alterada por seu Protocolo. ${ }^{72} \mathrm{O}$ Brasil participou da constituição do Sistema econômico latino-americano, assinado na cidade do Panamá, em 17 de outubro de $1975,{ }^{73}$ e do tratado da Associação latino-americana de integração, assinado em Montevidéu, em 12 de agosto de $1980,{ }^{74}$ do tratado da Bacia do Prata, assinado em Brasília, em 23 de março de 1970, ${ }^{75}$ bem como do tratado de cooperação amazônica, assinado em Brasília, em 3 de julho de $1978 .{ }^{76}$

Diversas convenções relativas ao espaço aéreo foram promulgadas nessa época: a Convenção sobre crimes e outros atos cometidos a bordo de aeronaves, celebrada em Tóquio, em 14 de setembro de 1963, e assinada em 28 de fevereiro de $1969,{ }^{77}$ a Convenção para a unificação normativa referente ao transporte aéreo internacional, complementar à Convenção de Varsóvia, assinada em Guadalajara, em 16 de setembro de $1961,{ }^{78}$ e a Convenção para a supressão de atos ilegais contra a segurança da aviação civil, assinada em Montreal, em 23 de setembro de 1971. ${ }^{79}$

Nesse período, também, o Brasil amplia o seu mar territorial primeiro para doze e, em seguida, para duzentas milhas náuticas. ${ }^{80}$ A respeito, pondera VMR: "Como país com extenso litoral e engajamento na facção territorialista, o Brasil participou intensamente das negociações e ratificou a Convenção das Nações Unidas sobre o Direito do Mar, assinada em 10 de dezembro de 1982". ${ }^{81}$ V. Marotta Rangel analisa o conceito de plataforma continental, adotado na Convenção de 1982, em curso na Haia (1985). ${ }^{82}$ Além desta, o Brasil assina e ratifica vários outros atos internacionais, em matéria de Direito do $\operatorname{Mar}^{83}$

71 Cf. Dec. n. 66.774, de 24 jun. 1970.

72 Cf. Dec. n. 67.542, de 12 nov. 1970.

73 Cf. Dec. n. 78.018, de 12 jul. 1976.

74 Cf. Dec. n. 87.054, de 23 mar. 1982.

75 River Plate Basis treaty; cf. Dec. n. 67.084, de 1 de março de 1970.

76 Cf. Dec. n. 85.050, de 18 ago. 1980.

77 Convention on offences and certain other acts committed on board aircraft; cf. Dec. n. 66.520, de 30 abr. 1969; v. tb. CASELLA, P. B. Direito internacional, terrorismo e aviação civil. São Paulo: Quartier Latin, 2006; cfr. item ref. Convenção de Tóquio, 1963.

78 Cf. Dec. n. 60.967, de 7 jul. 1967.

79 Convention for the suppression of unlawful acts against the safety of civil aviation; cf. Dec. n. 72.383, de 20 jun. 1973; v. tb. CASELLA, P. B. Direito internacional, terrorismo e aviação civil. São Paulo: Quartier Latin, 2006; cfr. item ref. Convenção de Montreal, 1971; McWHINNEY, E. The illegal diversion of aircraft and international law. Recueil des Cours, v. 138, p. 261-372, 1973.

80 Respectivamente, Dec.-lei n. 553, de 25 abr. 1969 e 1098, de 25 mar. 1970.

81 Em vigor, internacionalmente, desde 16 de novembro de 1994; no Brasil: aprovada pelo Dec.-leg. n. 5, 9 nov. 1987; ratificada em 22 dez. 1988; promulgada pelo Dec. n. 1.530, de 22 jun. 1995.

82 RANGEL, Vicente Marotta. Le plateau continental dans la Convention de 1982 sur le droit de la mer. Recueil de Cours, v. 5, n. 194, p. 269-428, 1985.

83 RANGEL, Vicente Marotta. Public international law: the last five decades. In: DOLINGER, Jacob; ROSENN, Keith (Ed.). A panorama of Brazilian Law. Miami / Rio de Janeiro: Univ. of Miami North-South 
A respeito do regime estipulado pela Constituição presente (1988-1990), ${ }^{84}$ poderia parecer surpreendente, que a Constituição vigente desde 5 de outubro de 1988 , não reitere dispositivos constitucionais relativos à solução pacífica de controvérsias e à proibição de guerras de conquista: isso é compreensível, enfatiza Marotta Rangel, porquanto normas cogentes do Direito Internacional "condenam qualquer agressão armada, mesmo não tendo propósito de conquista" ${ }^{85}$

Ao presidente da República são conferidos poderes exclusivos, em caso de agressão externa, para declarar guerra "autorizado ou ad referendum do Congresso Nacional", quando a agressão ocorra durante recesso parlamentar, bem como "declarar mobilização nacional, total ou parcial, nas mesmas condições". ${ }^{86}$

A Constituição vigente mantém a tradicional redação, atribuindo o poder específico ao presidente da República, para manter relações exteriores, mas inova ao conferir igualmente a este "acreditar os respectivos representantes diplomáticos". A Constituição, art. 84, inc. viii, também trouxe inovações em relação ao procedimento para a conclusão de tratados, pelo presidente da República, com a aprovação do Congresso Nacional. Nos termos do art. 49, inc. i, fica determinado ter o Congresso Nacional a prerrogativa de decidir, em última instância, a respeito de tratados, acordos ou atos que acarretem ônus para o Tesouro nacional. ${ }^{87}$

Center / Ed. Esplanada, 1992. p. 287-308. p. 300: Other Brazilian acts referring to maritime areas and activities include the following: the Convention on the safeguarding of human life at sea and the rules to prevent collisions at sea, adopted in London, 7 June 1960 [Dec. n. 60.696, de 8 maio 1967], the Convention for the regulation of whaling, signed in Washington, on 2 December 1946 [Dec. n. 73.497, de 17 jan. 1974], the Convention on civil liability for damage caused by oil pollution, signed in Brussels, on 29 November 1969 [Dec. n. 79.437, de 28 mar. 1977], the Convention on international regulations to avoid collisions at sea, signed in London, on 20 October 1972 [Dec. n. 80.068, de 2 ago. 1967], the Convention for the facilitation of international maritime traffic, signed in London, on 9 April 1965 [Dec. n. 80.068, de 7 nov. 1977], the Convention for the conservation of tuna and other related fish of the Atlantic, signed in Rio de Janeiro, on 14 May 1966 [Dec. n. 65.026, de 20 ago. 1969], the Convention for the prevention of pollution caused by ships, concluded in London, on 2 November 1973, and its respective Protocol, signed in the same city on 17 February 1978 [both approved with reservations by Leg-Dec. n. 4, 1987], and the Convention on cargo lines, signed in London, on 5 April 1966 [Dec. n. 66.103, de 22 jan. 1970].

84 RANGEL, Vicente Marotta. Public international law: the last five decades. In: DOLINGER, Jacob; ROSENN, Keith (Ed.). A panorama of Brazilian Law. Miami / Rio de Janeiro: Univ. of Miami North-South Center / Ed. Esplanada, 1992. p. 287-308. (item v, 'the present constitution (1988-1990)', p. 305-308).

85 RANGEL, Vicente Marotta. Public international law: the last five decades. In: DOLINGER, Jacob; ROSENN, Keith (Ed.). A panorama of Brazilian Law. Miami / Rio de Janeiro: Univ. of Miami NorthSouth Center / Ed. Esplanada, 1992. p. 287-308. p. 305: "The present Constitution preferred to note its commitment 'to the peaceful resolution of controversies' (preamble), and to include among the principles of international relations, that of defending peace and of peaceful resolution of conflicts [Const. 1988, art. 4 (vi) and (vii)]. Such principles are sufficient to indicate a commitment identical to prior commitments i.e, to the peaceful resolution of conflicts."

${ }^{86}$ Constituição da República, 1988, art. 84 (xix).

87 RANGEL, Vicente Marotta. Public international law: the last five decades. In: DOLINGER, Jacob; ROSENN, Keith (Ed.). A panorama of Brazilian Law. Miami / Rio de Janeiro: Univ. of Miami North-South 
Inovação foi também introduzida com relação à jurisdição dos tribunais, para decidirem questões trabalhistas contra estados estrangeiros ${ }^{88} \mathrm{~A}$ redação constitucional foi infeliz ao incluir, dentre propriedade do Governo Federal (e, por conseguinte, do Brasil) "os recursos naturais da plataforma continental", nos termos do art. 20, inc. v; a anterior incluía a própria plataforma (art. 4, inc. iii), o que significava que os recursos naturais, como acessórios seguem o principal, também eram nossos. A mudança da redação nada contribuiu para a clareza da determinação da extensão do território nacional.

Em sua tese a respeito Do conflito entre a Carta das Nações Unidas e os demais acordos internacionais (1954), ${ }^{89}$ ensina: "A formulação de objetivos, tão nobres e transcendentes, situa a Carta, na perspectiva do roteiro luminoso, que encontra nas Conferências da Paz de 1899 e de 1907, e na formação da Sociedade das Nações, balizas eminentes. Poderíamos, pois, dizer - parafraseando um texto de La Pradelle - que à Carta assoma o terceiro momento da esperança humana".90

Torna-se catedrático de Direito Internacional Público, em 1966, com tese sobre Natureza jurídica e delimitação do mar territorial (1964, segunda edição, revista, 1970). ${ }^{91}$ Já aí se inscreve o Direito do Mar, em momento decisivo, na vida e na obra do mestre, mas também igualmente oportuno e relevante, para o país e para o mundo, quando se aventurara o Brasil a adotar a lei que nos fazia ter mar territorial de 200 milhas. Antes

Center / Ed. Esplanada, 1992. p. 287-308. p. 306: "The vehement debates that arose over the legality of the foreign loan agreements contracted by the federal government, which resulted in the growth of the foreign debt, surely explain the wording of article 52 (iv) of this Constitution, in which any mention of 'foreign accords' was removed. Under the new provision, only the federal senate has the power to 'authorize foreign financial transactions of interest to the federal government, states, federal district, territories and counties' [art. $52(\mathrm{v})]$. The federal senate retains its prerogative of approving the heads of permanent diplomatic missions, even though the 1988 introduces a change in language from the corresponding provision in the 1969 Constitutional amendment. The change consists in adding that approval will be given 'after debate in a closed session'. Not only is the vote secret, but so too is the debate on the person nominated by the president of the republic to be the head of a permanent diplomatic mission."

88 RANGEL, Vicente Marotta. Public international law: the last five decades. In: DOLINGER, Jacob; ROSENN, Keith (Ed.). A panorama of Brazilian Law. Miami / Rio de Janeiro: Univ. of Miami NorthSouth Center / Ed. Esplanada, 1992. p. 287-308. p. 307: "Prior Constitutions contained a conflict between the generic jurisdiction ratione personae of the federal district courts, and the generic jurisdiction, which judicial bodies formerly had to resolve, has today been decided in favor of the labor courts. Under article 14 of the present Constitution, 'the labor court system has the power to conciliate and adjudicate individual and collective labor disputes, between workers and employers, including foreign public entities ...".

89 RANGEL, Vicente Marotta. Do conflito entre a Carta das Nações Unidas e os demais acordos internacionais. 1954. (Tese de Livre-Docência) - Faculdade de Direito, Universidade de São Paulo, São Paulo, 1954.

90 RANGEL, Vicente Marotta. Do conflito entre a Carta das Nações Unidas e os demais acordos internacionais. 1954. (Tese de Livre-Docência) - Faculdade de Direito, Universidade de São Paulo, São Paulo, 1954. p. 20, cita LA PRADELLE, A. de. Les grands cas de la jurisprudence internationale. Paris: Les éditions internationales, 1938. p. 29 e 40.

91 RANGEL, Vicente Marotta. Natureza jurídica e delimitação do mar territorial. 2. ed. rev. São Paulo: Revista dos Tribunais, 1970. 
de ser a matéria consolidada pela Convenção das Nações Unidas para o Direito do Mar, de 1982.

A extensão do mar territorial para 200 milhas marítimas, inicialmente de modo unilateral, como apontava V. Marotta Rangel (1966 e 1970) ${ }^{92}$ e, posteriormente, com fundamento na Convenção das Nações Unidas sobre o Direito do Mar, celebrada em Montego Bay, na Jamaica, em 1982, estabeleceu o mar territorial de 12 milhas e uma zona econômica exclusiva de 200 milhas. ${ }^{93}$

Opina Vicente Marotta Rangel (1992):94 "apesar de algumas tendências específicas, em diferentes períodos, pode-se apontar a persistência, durante o último meio século, de elementos intrínsecos, substancialmente consistentes e constantes", ${ }^{95}$ que represente não somente a continuação, mas a complementação dos períodos precedentes, e como inscritos na vigente Constituição da república, reflitam a ordem internacional, que por meio da prática, da jurisprudência e da doutrina, farão a contribuição no sentido da estruturação crescente e do aprimoramento do Direito Internacional.

Qual é a "efetividade da justiça nas relações internacionais". Esse dilema legitimidade - efetividade estará sempre presente. Como indaga V. Marotta Rangel (1994). ${ }^{96}$

A respeito da Sociedade das Nações: "embora eficiente na solução de conflitos na Europa e na América latina, a SdN se revelou incapacitada de evitar a segunda guerra mundial", conforme V. Marotta Rangel (2005). ${ }^{97}$

92 RANGEL, Vicente Marotta. Natureza jurídica e delimitação do mar territorial. 2. ed. rev. São Paulo: Revista dos Tribunais, 1970: “A Constituição brasileira passou a mencionar, entre os bens da União, 'o mar territorial' (art. 4 , n. vi, da Emenda constitucional n. 1, de 17 de outubro de 1969). Bem o fez. A legislação ordinária - no tocante à superfície desse mar - três vezes se modificou, para contemplar, finalmente, a regra das duzentas milhas marítimas. Estamos a sentir o influxo do chamado processo revolucionário sobre as regras do direito do mar."

93 DALLARI, Pedro Bohomoletz de Abreu. op. cit., p. 15-16.

94 RANGEL, Vicente Marotta. Public international law: the last five decades. In: DOLINGER, Jacob; ROSENN, Keith (Ed.). A panorama of Brazilian Law. Miami / Rio de Janeiro: Univ. of Miami North-South Center / Ed. Esplanada, 1992. p. 287-308.

95 RANGEL, Vicente Marotta. Public international law: the last five decades. In: DOLINGER, Jacob; ROSENN, Keith (Ed.). A panorama of Brazilian Law. Miami / Rio de Janeiro: Univ. of Miami North-South Center / Ed. Esplanada, 1992. p. 287-308. p. 308: "At the end of a necessarily incomplete overview of public international law in Brazil during the last five decades" (...).

96 RANGEL, Vicente Marotta. Sobre la efectividad de la justicia en las relaciones internacionales. In: RAMAMONTALDO, Manuel (Dir.). El derecho internacional en un mundo en transformación: liber amicorum en homenaje al profesor Eduardo Jiménez de Aréchaga. Montevideo: Fundación de Cultura Universitaria, 1994. p. 173-179.

97 RANGEL, Vicente Marotta. Direito e relações internacionais. 8. ed. São Paulo: Revista dos Tribunais, 2005. p. 17, nota 3): "Iniciou-se formalmente em 10 de janeiro de 1920, mercê da entrada em vigor do Tratado de Versalhes. Foi dissolvida em sua $21^{\mathrm{a}}$ sessão, ocorrida em Genebra, de 8 a 18 de abril de 1946.0 seu patrimônio foi então transferido para a ONU. Cessou de ter existência jurídica em 31 de julho de 1947." 
A respeito do "conflito entre a Carta das Nações Unidas e os demais acordos internacionais" (1954) $)^{98}$ ensina VMR, no sentido de apontar a "distinção marcante entre a Carta da ONU e os demais tratados; acordos que podemos chamar de constitucionais e acordos que reclamam a designação de ordinários; aqueles que, em determinado ordenamento jurídico, são hierarquicamente superiores aos que a esse ordenamento pertencem, e aqueles que não o são": "essa distinção possui bases firmes no direito internacional positivo; permanece, não obstante, despercebida e vaga, sem que os diferentes sistemas de classificações de tratados lhe destaquem, ou o façam suficientemente, os contornos, os efeitos, a importância". 99

A Corte passaria a ser - como deve - o centro de gravidade do sistema, almeja V. Marotta Rangel: "alma do progresso jurídico", "intérprete da Carta", "sem esquecer, porém, que as obrigações destas decorrentes preponderam sobre as 'resultantes de qualquer outro acordo internacional', e não, como se pretendera, ao término da conferência de São Francisco, e no âmbito do Comité de coordenação, sobre 'qualquer outra obrigação internacional', de tal modo que "as disposições da Carta prevalecem sobre as dos demais acordos; tanto quanto as da moral - lícito nos seja concluir - prevalecem sobre as da própria Carta". ${ }^{100}$

98 RANGEL, Vicente Marotta. Do conflito entre a Carta das Nações Unidas e os demais acordos internacionais. 1954. (Tese de Livre-Docência) - Faculdade de Direito, Universidade de São Paulo, São Paulo, 1954; na epígrafe do volume citava Lafayette R. Pereira, "Princípios de direito internacional" (1902, t. i, 'introdução', p. viii): "E dia virá em que os povos, grandes e pequenos, hão de compreender com uma clareza invencível que o respeito ao direito não é só um dever, mas também a condição necessária para a paz e, em conseqüência, para a riqueza, o engrandecimento e a felicidade de todos."

99 RANGEL, Vicente Marotta. Do conflito entre a Carta das Nações Unidas e os demais acordos internacionais. 1954. (Tese de Livre-Docência) - Faculdade de Direito, Universidade de São Paulo, São Paulo, 1954. 'conclusões', p. 121-124.

100 RANGEL, Vicente Marotta. Do conflito entre a Carta das Nações Unidas e os demais acordos internacionais. 1954. (Tese de Livre-Docência) - Faculdade de Direito, Universidade de São Paulo, São Paulo, 1954. p. 124; e a seguir, ‘introdução', p. 15-29, cit. p. 15 e p. 19-20: “As desinquietações políticas e sociais, envoltas em ressentimento e ameaça, precursoras da última grande guerra, serviram para acusar a deficiência do antigo ordenamento jurídico internacional. Instrumento precário, sujeito a descrédito, rejeitado por vários estados, alguns dos quais poderosos, mostrou-se o Covenant da Sociedade das Nações impróprio a conjurar a grave crise, que, enraizada na própria conferência de Versalhes, sacudiu e talou, anos a fio, a humanidade. O procedimento de revisão da carta de Genebra apresentava-se, ao demais, sobremodo complexo, vinculado a severas prescrições técnicas, de sorte que as vicissitudes das relações internacionais acabaram por torná-lo inexeqüível. / Tanto que se intensificaram os eventos bélicos, e antes que se dissolvesse a sociedade, não foram poucos os estudos que se promoveram, colimando-lhe a reforma ou a substituição." (...) "Assim como surgiu o Pacto da primeira guerra mundial, da segunda surgiu a Carta. A última conflagração havia tumultuado e fendido o sistema de relações internacionais; mister se fazia restabelecê-lo, aperfeiçoá-lo, assentá-lo em bases mais sólidas, ressalvada a segurança dos povos, discernidos os ensinamentos do passado. E, se bem que em alguns pontos se possa increpá-la de inferior ao Pacto, mormente no que tange ao procedimento de votação no Conselho de Segurança, apresenta-se a Carta como documento que, de certa forma, atesta nível mais elevado de solidariedade interestatal, como o denota o fato de haver repelido o tradicional princípio da unanimidade das decisões. Reflexo da momentosa quadra histórica em que vingou, exprime, como o dispõe o Preâmbulo, o desejo das nações vitoriosas de preservarem as gerações 
Ainda a respeito da ONU, observa V. Marotta Rangel (2005):

o Conselho de Segurança é o único órgão com poder de tomar decisões que os membros das Nações Unidas concordam em aceitar e executar. Os demais órgãos formulam recomendações, as quais não possuem o mesmo nível de obrigatoriedade. ${ }^{101}$

A respeito da "equidade em Direito Internacional", para Vicente Marotta Rangel (1989) ${ }^{102}$ haveria a necessidade de reportar-se, para a compreensão desta, a Aristóteles, em suas meditações sobre a felicidade, "que é resultado, não da razão mas da virtude". ${ }^{103}$ No exame de tais relações, Aristóteles comenta o mesmo embaraço, apontado por outros que também abordaram a questão, no tocante às relações entre a equidade e a justiça, nunca claramente determinadas e que a natureza da equidade permanece circundada de mistério. Aristóteles dividia a virtude política, em justiça legal, que é convencional e variável, e justiça natural, que não depende nem das opiniões nem dos decretos dos homens, e tem caráter universal e imutável. Sobre tal distinção funda a teoria da equidade.

A busca do sentido da justiça, que começou nos corredores da Academia de Atenas, ainda é uma história inacabada, como observa Marotta Rangel, onde a equidade desempenha estranho papel, na estrutura do direito: separada deste, faz, contudo, parte dele. $^{104}$

Analisando "desenvolvimentos recentes" da "equidade em Direito Internacional" Vicente Marotta Rangel (1989) ${ }^{105}$ apontava a necessidade de reportar-se, para a compreensão desta, a Aristóteles, em suas meditações sobre a felicidade, "que é resultado, não da razão mas da virtude": ${ }^{106}$ o Estagirita atribui grande importância às

vindouras do flagelo da guerra, de estabelecerem princípios de justiça, igualdade e respeito às obrigações internacionais, e de promoverem 'o progresso social e melhores condições de vida, dentro de uma liberdade mais ampla'. Também, o de praticarem a tolerância e as regras de boa vizinhança, e garantirem o uso da força armada apenas no interesse comum. A formulação de objetivos, tão nobres e transcendentes, situa a Carta, na perspectiva do roteiro luminoso, que encontra nas Conferências de paz de 1899 e de 1907, e na formação da Sociedade das Nações, balizas eminentes."

101 RANGEL, Vicente Marotta. Direito e relações internacionais. 8. ed. São Paulo: Revista dos Tribunais, 2005. nota 14 ao art. 25 da Carta da ONU, p. 33.

102 RANGEL, Vicente Marotta. L'equité en droit international: des développements récents. Tessaloniki: Aristoteleio Panepistimio, 1989. p. 937-950. (separata). p. 937: “capítulo que foi, a justo título, qualificado um dos mais notáveis dessa obra".

103 RANGEL, Vicente Marotta. L'equité en droit international: des développements récents. Tessaloniki: Aristoteleio Panepistimio, 1989. p. 937-950. (separata). p. 937-938.

104 Ver tb. NEWMANN, Ralph A. Equity in the world's legal systems. Bruxelles: Bruylant, 1973. 'introduction', p. 15.

105 RANGEL, Vicente Marotta. L'equité en droit international: des développements récents. Tessaloniki: Aristoteleio Panepistimio, 1989. p. 937-950. (separata).

106 RANGEL, Vicente Marotta. L'equité en droit international: des développements récents. Tessaloniki: 
relações entre a justiça e a equidade, e a esta dedica o capítulo x do livro v da Ética a Nicômaco. ${ }^{107}$

A proteção da civilização como legado da humanidade pode e deve ser vista e regulamentada em perspectiva mais abrangente, como ressalta V. Marotta Rangel (1994): ${ }^{108}$ o processo de unificação legislativa tem sido ultimamente dinamizado, graças ao influxo das organizações internacionais (especificamente em matéria de proteção de bens culturais, caberia ressaltar a contribuição da UNIDROIT e o exemplo interessante de cooperação deste instituto com a UNESCO).

Enfatiza VMR que a proteção de bens culturais não mais se realiza somente em contexto nacional: a intensificação do comércio acabou por determinar a internacionalização desses bens, em cujo âmbito não se pode ignorar o conflito de interesses econômico e político, existente entre estados exportadores e estados importadores desses bens. $^{109}$

A obra de Emer de Vattel, O direito das gentes (1758), foi traduzida e recebeu estudo introdutório de V. Marotta Rangel (2004): “o tratado de Vattel é uma das principais obras escritas no século XVIII», ${ }^{110}$ embora se possa questionar qual a importância da inovação de Vattel, e tenha caráter próprio e relevante, em relação às ideias de seu mestre Wolff.

Aristoteleio Panepistimio, 1989. p. 937-950. (separata). p. 937-938; v. tb. FAVRE, Antoine. Principes du droit des gens. Fribourg: Libr. de droit et de jurisprudence / Éd. interuniv., 1974. Item 18, n. iii, 'equité', p. 292-294: "La notion d'equité déborde le domaine du droit. Elle comporte des acceptions différentes qu'il faut définir" e remete, a seguir, igualmente, a Aristóteles.

107 RANGEL, Vicente Marotta. L'equité en droit international: des développements récents. Tessaloniki: Aristoteleio Panepistimio, 1989. p. 937-950. (separata): "capítulo que foi, a justo título, qualificado um dos mais notáveis dessa obra"; ARISTÓTELES. Ética a Nicômaco. Trad. de Leonel Vallandro e Gerd Bornheim da versão inglesa de W. D. Rosá. São Paulo: Abril, 1973. p. 245-436, livro v, cap. x, p. 336-337: "o eqüitativo, embora superior a uma espécie de justiça, é justo, e não é como coisa de classe diferente que é melhor do que o justo. A mesma coisa, pois, é justa e eqüitativa, e, embora ambos sejam bons, o eqüitativo é superior".

108 RANGEL, Vicente Marotta. Objetos culturais: o recente projeto UNIDROIT de convenção internacional. In: BAPTISTA, L. O.; HUCK, H. M.; CASELLA, P. B. (Org.). Direito e comércio internacional: tendências e perspectivas: estudos em homenagem ao prof. Irineu Strenger. São Paulo: LTr, 1994. p. 213-220.

109 RANGEL, Vicente Marotta. Objetos culturais: o recente projeto UNIDROIT de convenção internacional. In: BAPTISTA, L. O.; HUCK, H. M.; CASELLA, P. B. (Org.). Direito e comércio internacional: tendências e perspectivas: estudos em homenagem ao prof. Irineu Strenger. São Paulo: LTr, 1994. p. 213-220. p. 219220.

110 VATTEL, Emer de. O direito das gentes. Prefácio e tradução de V. Marotta Rangel. Brasília: IPRI - UnB, 2004; "prefácio", p. xlvii ss.), Vicente Marotta Rangel frisa "para situar-nos apenas no âmbito do direito internacional, cabe lembrar que assim como o "De jure belli ac pacis", de Hugo Grócio, exerceu no século xvii maior influência que os ensinamentos de Francisco de Vitória, o tratado de Vattel eclipsou, como assinala REUTER, Paul. Institutions internationales. Paris: PUF, 1955. p. 47; tão logo publicado, o livro do jurisconsulto holandês." 
Ressalta VMR, sob o prisma doutrinário,

Vattel difere dos antecessores, à medida que introduz separação mais nítida entre direito natural e direito positivo, entre moral e direito, contribuindo, de certo modo, para o fortalecimento do voluntarismo jurídico, que até hoje tem infelizmente persistido. ${ }^{111}$

A respeito da contribuição de Vattel (1758, ed. bras. 2004) considera VMR louvável manifestar-se este "contrário à redução do direito das gentes ao direito positivo", pois "sublinha o autor, esse entendimento importaria em 'restringir a limites muito estreitos' o direito das gentes e consistiria, ao mesmo tempo, em 'degradá-lo, ao desconhecer a sua verdadeira origem'." 112

Particular relevância tem a voz, autorizada e ponderada, de V. Marotta Rangel (2005) $)^{113}$ observa manter-se o art. 51 "de constante atualidade" e se levanta contra a utilização abusiva desse 'direito de legítima defesa' em duas situações recentes, igualmente controvertidas, mas nas quais, excetuadas as hipóteses de engajamentos que excluam a racionalidade do exame das causas e dos efeitos, impõe-se descartar essa alegação de legítima defesa: ${ }^{114}$ de Israel, em relação à construção do muro e aos atentados da resistência contra a ocupação dos territórios ocupados, desde 1967, porquanto, como ressaltou a Corte Internacional de Justiça (parecer de 9 de julho de 2004), ${ }^{115}$ é a ocupação que deu causa ao movimento de resistência, e portanto não pode ser a ocorrência da resistência o argumento utilizado, quando quem o invoca foi o causador do quadro de violação do Direito Internacional, instaurado desde 1967, pela ocupação dos territórios palestinos. $^{116}$

111 VATTEL, Emer de. O direito das gentes. Prefácio e tradução de V. Marotta Rangel. Brasília: IPRI - UnB, 2004. p. lvi e p. lxii: "O tratado reflete a realidade das relações políticas internas e internacionais da época em que foi escrito, sem ignorar as contribuições do pretérito em relação aos diversos tópicos nele examinados. Essa realidade induziu Vattel a tentar aclarar a tormentosa dialética entre soberania e direito internacional".

112 VATTEL, Emer de. O direito das gentes. Prefácio e tradução de V. Marotta Rangel. Brasília: IPRI - UnB, 2004. p. lxv-lxvi.

113 RANGEL, Vicente Marotta. Direito e relações internacionais. 8. ed. São Paulo: Revista dos Tribunais, 2005. nota 20, p. 38.

114 O mesmo princípio, com pequenas diferenças de formulação, consagra os direitos internos como o direito internacional: se o ato é consequência direta da ação de quem, em primeiro lugar, lhe deu causa, exclui-se a viabilidade de tal invocação.

115 C.I.J., parecer consultivo, prolatado em 9 de julho de 2004, a respeito das consequências jurídicas da construção do muro nos territórios palestinos ocupados. Análise deste, em CASELLA, P. B. Fundamentos do direito internacional pós-moderno. Prólogo Hugo Caminos. São Paulo: Quartier Latin, 2008. (item xvii, 'política e moral'), ao qual se remete.

116 RANGEL, Vicente Marotta. Direito e relações internacionais. 8. ed. São Paulo: Revista dos Tribunais, 2005. nota 20, p. 38; RANGEL, Vicente Marotta. L'avis consultatif du 9 juillet 2004 et l'antinomie entre volontarisme et solidarisme. In: International law and the use of force at the turn of centuries: essays in honour of Vladimir-Djuro Degan. Rijeka: Faculty of Law, Univ. of Rijeka, 2005. p. 199-205. 
A mutação essencial em curso no Direito Internacional pós-moderno é apontada por V. Marotta Rangel $(2005)^{117}$ ao avaliar a contribuição da Corte Internacional de Justiça, no Parecer sobre as consequências jurídicas da construção do muro, nos territórios palestinos ocupados (2004), no contexto regional específico:

em razão do regime jurídico relativamente recente desse território, sobre o qual o Conselho de Segurança e a Assembléia geral ainda desempenham papel primordial, compreende-se a atenção consagrada pela Corte às decisões tomadas a respeito por esses dois órgãos, a partir da Resolução 181 (II) da Assembléia geral, de 29 de novembro de 1947, e da Resolução 62 do Conselho de segurança, de 16 de novembro de 1948, que dizem respeito ao estabelecimento desse regime.

Tendo as forças israelenses ocupado, no conflito armado de 1967, o conjunto dos territórios que tinham constituído a Palestina sob mandato britânico ${ }^{118}$ (compreendendo os territórios designados sob nome de Cisjordânia, situados a leste da denominada 'linha verde'), a Resolução n. 242 (1967) do Conselho de Segurança, já tinha assinalado a inadmissibilidade da aquisição de território pela guerra e chamado à "cessação de todas as assertivas de beligerância e de todos os estados de beligerância". Segundo o Parecer consultivo de 9 de julho de 2004, “o conjunto de tais territórios (inclusive Jerusalém oriental) permanecem territórios ocupados e Israel conservou a condição de potência ocupante". ${ }^{119}$

Ressalta Marotta Rangel (2005) ${ }^{120}$ terem “os dois órgãos igualmente reconhecido a aplicabilidade de jure da IV Convenção de Genebra relativa à proteção de

117 RANGEL, Vicente Marotta. L'avis consultatif du 9 juillet 2004 et l'antinomie entre volontarisme et solidarisme. In: International law and the use of force at the turn of centuries: essays in honour of VladimirDjuro Degan. Rijeka: Faculty of Law, Univ. of Rijeka, 2005. p. 199-205. p. 200: “À la fin de l'étude sur la Révolution française et en particulier sur le Projet de la déclaration de droit des gens de l'abbé Grégoire, le professeur Degan établit un parallélisme entre le droit naturel et le droit positif, pour en dégager la supériorité du premier à l'égard du deuxième. En nous prévenant du danger du rationalisme, il nous signale ensuite: 'en ce qui concerne les principes du droit naturel pur, bien qu'ils ne soient protégés comme tels par une sanction, les conséquences néfastes de leur infraction sont inévitables dans quelques conditions qu'elles sont atteintes ou voulues'."

118 ASBECK, Frederik M. van (Baron). Le statut actuel des pays non-autonomes d'outremer. Recueil des Cours, v. 71, n. 2, p. 345-476, 1947.

119 C.I.J., Conseqüências jurídicas da construção do muro nos territórios palestinos ocupados (parecer consultivo de 9 de julho de 2004, parágrafos 74-78, mais adiante, par. 88) invoca a Corte a Resolução n. $2.625(\mathrm{XXV})$ da AGNU lembrando "tout état a le devoir de s'abstenir de toute mesure de coercion qui priverait de leur droit à l'autodétermination (...) les peuples mentionnés (dans la dite résolution).”

120 RANGEL, Vicente Marotta. L'avis consultatif du 9 juillet 2004 et l'antinomie entre volontarisme et solidarisme. In: International law and the use of force at the turn of centuries: essays in honour of VladimirDjuro Degan. Rijeka: Faculty of Law, Univ. of Rijeka, 2005. p. 199-205. p. 202; C.I.J., Conseqüências jurídicas da construção do muro nos territórios palestinos ocupados (parecer consultivo de 9 de julho de 
civis em tempo de guerra, de 12 de agosto de 1949, aos territórios ocupados, desde 1967", no que os acompanha a Corte Internacional de Justiça.

Enfatiza V. Marotta Rangel (2005), ${ }^{121}$ no tocante às relações entre o costume e as demais fontes do Direito Internacional, convém lembrar o reconhecimento pela Corte quanto ao fato de 'Israel não ser parte da IV Convenção da Haia, de 1907', à qual foi anexado o Regulamento que tinha por objeto 'revisar as leis e os costumes de guerra'. Mencionando a decisão do Tribunal militar internacional de Nurembergue, de 30 de setembro e de $1^{\circ}$ de outubro de 1946, bem como o Parecer consultivo de 8 de julho de 1996, sobre a licitude da ameaça ou do uso de armas nucleares, a Corte estimou integrarem os dispositivos do Regulamento da Haia de 1907 o caráter de Direito Internacional Consuetudinário. Constata, ainda a Corte, aplicando o Direito Internacional Consuetudinário, tal como este se reflete no art. 42 do Regulamento sobre as leis e os costumes da guerra terrestre, que "território é considerado ocupado quando se encontra, de fato, colocado sob a autoridade de exército inimigo, e a ocupação se estende somente aos territórios nos quais essa autoridade está estabelecida e em condições de exercer seu controle", dessa forma observando a Corte estar o conjunto dos territórios situados entre a linha verde e "a antiga fronteira oriental da Palestina, sob mandato britânico ocupados por Israel desde 1967". Esse estado conservou a condição de "potência ocupante" e, nessas condições, a sua responsabilidade não pode ser eximida.

Os princípios enunciados na Carta da ONU, art. $2^{\circ}$, par. $4^{\circ}$, com relação ao uso da força, bem como na Resolução n. 2.625 (XXV) da AGNU, são lembrados pela Corte, reportando-se ao caso das atividades militares e paramilitares na Nicarágua e contra esta (1986), para concluir que os princípios enunciados, com relação ao uso da força, lá são afirmados como integrantes e refletindo o Direito Internacional Consuetudinário. ${ }^{122}$ E acrescenta valer isso, igualmente, em relação ao corolário consistente na ilicitude de qualquer aquisição territorial resultante de ameaça ou de uso da força.

2004, pars. 98 a 101).

121 RANGEL, Vicente Marotta. L'avis consultatif du 9 juillet 2004 et l'antinomie entre volontarisme et solidarisme. In: International law and the use of force at the turn of centuries: essays in honour of VladimirDjuro Degan. Rijeka: Faculty of Law, Univ. of Rijeka, 2005. p. 199-205. p. 203; (C.I.J., licitude da ameaça ou do uso de armas nucleares, parecer consultivo de 8 de julho de 1996, Recueil, 1996, t. 1, p. 256, par. 75).

122 RANGEL, Vicente Marotta. L'avis consultatif du 9 juillet 2004 et l'antinomie entre volontarisme et solidarisme. In: International law and the use of force at the turn of centuries: essays in honour of Vladimir-Djuro Degan. Rijeka: Faculty of Law, Univ. of Rijeka, 2005. p. 199-205. p. 204; C.I.J., atividades militares e paramilitares na Nicarágua e contra esta, Nicarágua c. Estados Unidos (ordonnance en mesures conservatoires, 10 mai 1984; déclaration d'intervention de la République de El Salvador, ordonnance, 4 octobre 1984; compétence et recevabilité, ordonnance, 26 novembre 1984; fond, arrêt, 27 juin 1986; cit. Recueil, 1986, p. 98-101, pars. 187-190). 
A aproximação entre diversas fontes do Direito Internacional, observa V. Marotta Rangel (2005), ${ }^{123}$ parece levar ao reconhecimento de diversas obrigações erga omnes, que no caso, segundo a Corte, foram violadas: são estas obrigações, como precisara a Corte Internacional de Justiça no caso Barcelona traction (1970), que "dizem respeito a todos os estados" e, dada "a importância dos direitos em questão, todos os estados podem se considerar como tendo interesse jurídico em que tais direitos sejam assegurados". Identifica a Corte, no caso do Parecer (2004) duas ordens de obrigações erga omnes que teriam sido violadas: "a de respeitar o direito à autodeterminação do povo palestino" e a de determinadas obrigações específicas, tal como estipuladas pelo direito internacional humanitário. ${ }^{124}$

Em matéria de direito internacional humanitário desempenhou a Corte Internacional de Justiça papel primordial, como ilustra o julgamento no caso do estreito de Corfu (1949), ${ }^{125}$ e ressalta V. Marotta Rangel:

cumpre lembrar que dentre as obrigações incumbentes às autoridades albanesas, existiam aquelas consistentes 'em fazer conhecer, no interesse da navegação em geral, a existência de campo minado, nas águas territoriais albanesas, bem como advertir os navios de guerra britânicos, no momento em que estes se aproximavam, do perigo iminente ao qual os expunha esse campo de minas'. Tais obrigações foram fundadas, esclareceu então a Corte, não sobre a Convenção VIII da Haia, de 1907, que é aplicável em tempo de guerra, mas sobre certos princípios gerais, bem reconhecidos, tais como considerações elementares de humanidade, mais absolutas ainda em tempo de paz que de guerra, o princípio da liberdade das comunicações marítimas e a obrigação, para todos os estados, de não utilizar seu território para fins de atos contrários aos direitos de outros estados. ${ }^{126}$

123 RANGEL, Vicente Marotta. L'avis consultatif du 9 juillet 2004 et l'antinomie entre volontarisme et solidarisme. In: International law and the use of force at the turn of centuries: essays in honour of VladimirDjuro Degan. Rijeka: Faculty of Law, Univ. of Rijeka, 2005. p. 199-205; C.I.J., Barcelona traction light and power company, Bélgica c. Espanha (exceptions préliminaires, 24 juillet 1964; fond, 5 février 1970; cit. Recueil, 1970, p. 32, par. 33).

124 C.I.J., Conseqüencias jurídicas da construção do muro nos territórios palestinos ocupados (parecer consultivo de 9 de julho de 2004, par. 155); RANGEL, Vicente Marotta. L'avis consultatif du 9 juillet 2004 et l'antinomie entre volontarisme et solidarisme. In: International law and the use of force at the turn of centuries: essays in honour of Vladimir-Djuro Degan. Rijeka: Faculty of Law, Univ. of Rijeka, 2005. p. 199205. p. 204-205: "La mention au droit international humanitaire nous fait rejoindre un domaine du gens où la Cour joue encore un rôle primordial."

125 C.I.J., estreito de Corfu, Reino Unido c. Albânia (exceções preliminares, 25 de março de 1948; julgamento do mérito, 9 de abril de 1949; fixação do montante das reparações, 15 de dezembro de 1949).

126 RANGEL, Vicente Marotta. (cap. cit., 2005, p. 205); 
A tais princípios gerais reportou-se novamente à Corte Internacional de Justiça em, pelo menos, duas outras ocasiões, também referidas: a propósito das atividades militares e paramilitares na Nicarágua e contra esta (1986), bem como no Parecer consultivo de 8 de julho de 1996, sobre a licitude da ameaça ou do uso de armas nucleares (1996).

Insere-se o caso na antinomia entre duas concepções do Direito Internacional: voluntarista e solidarista, na linha de análise, à qual se reporta Marotta Rangel (2005), tal como desenvolvida por V. D. Degan (i.a., esp. 1996 e 1989). ${ }^{127}$

Para a concepção voluntarista, as normas de Direito Internacional somente podem ser decorrência da vontade dos estados. ${ }^{128}$ Para a concepção solidarista, a existência da comunidade internacional é um fato: as normas de Direito Internacional são decorrência das exigências dessa comunidade e visam alcançar objetivos reconhecidos pela humanidade. Enfatiza Degan a existência e o conteúdo de "princípios relacionados à responsabilidade dos estados que limitam a liberdade dos estados soberanos. Estes proscrevem a conduta irresponsável dos governos, nas suas relações recíprocas". ${ }^{129} \mathrm{E}$ aduz Marotta Rangel (2005): “o mesmo efeito resulta dos arts. 53 e 64 da Convenção de Viena sobre direito dos tratados, artigos que decorrem da aceitação das normas sobre o jus cogens."

Sem contestar o papel da vontade soberana dos estados, como o principal fator da criação ou do término das normas de Direito Positivo, ocorre que essa vontade seja as vezes dependente de determinadas normas de caráter objetivo (dependent on some objective norms), enquanto normas de Direito Internacional cogente: "as normas objetivas de direito internacional determinam ou ao menos restringem a capacidade de criação de

127 DEGAN, Vladimir-Djuro. Some objective features in international law. In: MAKARCZYK, Gerzy. (Ed.). Essays in honour of Krystof Skubiszewski. Haia: Kluwer Law International, 1996. p. 123-146; v. tb. DEGAN, Vladimir-Djuro. On state succession. In: CASELLA, P. B. (Org.). Dimensão internacional do direito: estudos em homenagem a G. E. do Nascimento e Silva. São Paulo: LTr, 2000. p. 118-140; DEGAN, Vladimir-Djuro. Création et disparition de l'état (à la lumière du démembrement de trois fédérations multiethniques en Europe). Recueil des Cours, v. 279, p. 195-375, 1999; DEGAN, VladimirDjuro. Traité et coutume dans le droit de la mer. In: BAPTISTA, L. O.; FONSECA, J. R. Franco da. (Org.). O direito internacional no terceiro milênio: estudos em homenagem ao prof. V. Marotta Rangel. São Paulo: LTr, 1998. p. 407-434; DEGAN, Vladimir-Djuro. La succession d'états en matière de traités et les états nouveaux. Annuaire Français de Droit International, v. 42, n. 1, p. 206-227, 1996; DEGAN, VladimirDjuro. L'affirmation des principes du droit naturel par la Révolution française. Annuaire Français de Droit International, v. 35, n. 1, p. 99-116, 1989.

128 DEGAN, Vladimir-Djuro. La succession d'états en matière de traités et les états nouveaux. Annuaire Français de Droit International, v. 42, n. 1, p. 206-227, 1996. p. 123: "The voluntarist concept strictly takes all legal rules as a product of the will of sovereign states."

129 DEGAN, Vladimir-Djuro. La succession d'états en matière de traités et les états nouveaux. Annuaire Français de Droit International, v. 42, n. 1, p. 206-227, 1996. p. 129: "some legal principles relating to state responsibility which really affect the freedom of sovereign states. They in fact out-law irresponsible conduct of governments in their mutual relations." 
normas pelos estados" e a tendência seria no sentido de que estas se expandam no século xxi, em função da consecução dos objetivos comuns da humanidade. ${ }^{130}$

Voltando à contraposição entre as teses voluntarista e solidarista, frisa V. Marotta Rangel (2005) $)^{131}$ saber-se quão claramente foi a primeira majoritária, na origem da Corte permanente de justiça internacional, como paradigmaticamente ilustra o julgamento desta, no caso do navio Lótus (1927):132 "as normas de direito internacional, vinculando as relações entre estados independentes, procedem da vontade destes", e tal vontade "se manifesta nas convenções ou nos usos geralmente aceitos como consagrando princípios de direito", onde "referido posicionamento em sentido claramente voluntarista não representava surpresa, porquanto fora este precedido por decisões arbitrais, não obstante oposições doutrinais", tal como Marcel Sibert (1951). ${ }^{133}$ Contudo, o positivismo, ao qual se filiava também a então existente doutrina soviética, ainda hoje "merece o apoio de parcela altamente representativa da doutrina, mas enfrenta a firme oposição de corrente composta por juristas igualmente ilustres", como Christian Tomuschat (1993, 1999), ${ }^{134}$ e "também, cumpre assinalar, pela jurisprudência contemporânea da Corte Internacional de Justiça, tal como no Parecer de 9 de julho de 2004."

Nesse sentido, frisa V. Marotta Rangel, dada a importância dos direitos em questão e as diferentes fontes em jogo, de modo a ultrapassar quadro de dimensão simplesmente consuetudinária ou regional, poderia ser compreendida a qualificação erga omnes, conferida a tais obrigações: ${ }^{135}$ "dado o grande alcance dessa qualificação, seríamos tentados a estabelecer assimilação entre a noção de erga omnes, à outra, mais conhecida, de jus cogens, tal como a menciona o art. 53 da Convenção de Viena sobre

130 DEGAN, Vladimir-Djuro. La succession d'états en matière de traités et les états nouveaux. Annuaire Français de Droit International, v. 42, n. 1, p. 206-227, 1996, p. 145-146: "In some situations of the operations of jus cogens, these objective norms even determine or at least restrain the law-creating power of sovereign states. (...) What can be expected in the $21^{\text {st }}$ century is a continued expansion of rules of this kind, deduced from the goals of mankind."

131 RANGEL, Vicente Marotta. L'avis consultatif du 9 juillet 2004 et l'antinomie entre volontarisme et solidarisme. In: International law and the use of force at the turn of centuries: essays in honour of VladimirDjuro Degan. Rijeka: Faculty of Law, Univ. of Rijeka, 2005. p. 199-205. par. 8, p. 205, b/c notas 10 e 11.

132 C.P.J.I., Lótus, França c. Turquia, julgamento de 7 de setembro de 1927: "Les règles de droit international liant les rapports entre états indépendants procèdent de la volonté de ceux-ci" (...) e tal vontade "se manifeste dans les conventions ou dans les usages acceptés généralement comme consacrant des principes de droit."

133 SIBERT, Marcel. Traité de droit international public. Paris: Dalloz, 1951. t. 1. p. 15: "Comment pourrait-on nier, devant ces citations, que le point de vue positiviste l'emporte, dans la jurisprudence, sur celui du droit naturel? Doit-on s'en féliciter, sans réserves? On en peut douter."

134 TOMUSCHAT, Christian. International law: ensuring the survival of mankind in the eve of a new century: general course on public international law. Recueil des Cours, v. 281, p. 9-438, 1999, e consideravelmente mais enfático em seu posterior curso geral, ___ _ . International law: ensuring the survival of mankind in the eve of a new century: general course on public international law. Recueil des Cours, v. 281, p. 9-438, 1999).

135 C.I.J., Conseqüências jurídicas da construção do muro nos territórios palestinos ocupados (parecer consultivo de 9 de julho de 2004, em sentido contrário, o voto da Juíza R. HIGGINS, pars. 37-39). 
direito dos tratados. Tal assimilação poderia, eventualmente, se destinar a suplementar as obscuridades que, todavia, circundam a primeira dessas noções, e que encontraria, apesar de tudo, a sua razão de ser no fato de, dentre outros motivos, que ambos os conceitos destinam-se a proteger interesses comuns dos estados e valores morais fundamentais". ${ }^{136}$

Também oportuna e necessária a sua lição: “a alegação de legítima defesa preventiva, para justificar o ataque ao Iraque, em março de 2003, também tem sido categoricamente rejeitada pelas mais autorizadas entidades representativas de direito internacional", 137

São Paulo, março de 2015.

\section{Referências}

ACCIOLY, Hildebrando. Manual de direito internacional público. São Paulo: Saraiva, 1957.

ACCIOLY, Hildebrando. Principes généraux de la responsabilité internationale d'après la doctrine et la jurisprudence. Recueil des Cours, v. 96, p. 349-442, 1959.

ARAÚJO, João Hermes Pereira de. A processualística dos atos internacionais no Brasil. Rio de Janeiro: MRE, 1958.

ARISTÓTELES. Ética a Nicômaco. Trad. de Leonel Vallandro e Gerd Bornheim da versão inglesa de W. D. Rosá. São Paulo: Abril, 1973.

ARRUDA, Brás de Souza. Curso de direito internacional: na era atômica. Curitiba: Guaíra ed., 1920.

ARRUDA, Brás de Souza. Estrutura do direito internacional. Revista da Faculdade de Direito da Universidade de São Paulo, São Paulo, v. 58, p. 32-92, 1963.

ASBECK, Frederik M. van (Baron). Le statut actuel des pays non-autonomes d'outremer. Recueil des Cours, v. 71, n. 2, p. 345-476, 1947.

BAPTISTA, Luiz Olavo; FONSECA, José Roberto Franco da (Coord.). O direito internacional no terceiro milênio: estudos em homenagem ao professor Vicente Marotta Rangel. São Paulo: LTr, 1998. p. 17-24.

\footnotetext{
136 RANGEL, Vicente Marotta. L'avis consultatif du 9 juillet 2004 et l'antinomie entre volontarisme et solidarisme. In: International law and the use of force at the turn of centuries: essays in honour of VladimirDjuro Degan. Rijeka: Faculty of Law, Univ. of Rijeka, 2005. p. 199-205. p. 204; b/c notas 7 e 8; tb. cita CASSESE, Antonio. Le droit international dans un monde divisé. Paris: Berger-Levrault, 1986 e RAGAZZI, Maurizio. The concept of international obligations erga omnes. Oxford: Clarendon Press, 1997. p. 72.

137 RANGEL, Vicente Marotta. L'avis consultatif du 9 juillet 2004 et l'antinomie entre volontarisme et solidarisme. In: International law and the use of force at the turn of centuries: essays in honour of VladimirDjuro Degan. Rijeka: Faculty of Law, Univ. of Rijeka, 2005. p. 199-205.
} 
BEVILAQUA, C. Direito público internacional: a synthese dos princípios e a contribuição do Brasil. Rio de Janeiro: Freitas Bastos, 1910.

BEVILAQUA, C. Direito público internacional: a synthese dos princípios e a contribuição do Brasil. 2. ed. Rio de Janeiro: Freitas Bastos, 1939.

BOSON, Gerson de Brito Mello. Curso de direito internacional público. Belo Horizonte: B. Álvares, 1958.

BOSON, Gerson de Brito Mello. Direito internacional público: o estado em direito das gentes. Belo Horizonte: Del Rey, 1994.

BOSON, Gerson de Brito Mello. O homem como sujeito de direito internacional. Belo Horizonte: [s.n.], 1951.

CÂMARA, José Sette. The ratification of international treaties. Toronto: The Ontario publishing company, 1949.

CASELlA, P. B. ABZ ensaios didáticos. Prefácio de João Grandino Rodas. São Paulo: Imprensa Oficial, 2008.

CASELLA, P. B. Cem anos do direito internacional público (1913) de José Mendes (1861-1918) - olhar reflexivo sobre o direito internacional nas Arcadas (1911-1918). Revista da Faculdade de Direito da Universidade de São Paulo, São Paulo, 2013, v. 108, p. 27-44, jan./dez. 2013.

CASElLA, P. B. Direito internacional dos espaços. São Paulo: Atlas, 2009.

CASELLA, P. B. Direito internacional no tempo antigo. São Paulo: Atlas, 2012.

CASELLA, P. B. Direito internacional no tempo medieval e moderno até Vitória. São Paulo: Atlas, 2012 .

CASELlA, P. B. Direito internacional no tempo moderno de Suarez a Grócio. São Paulo: Atlas, 2014.

CASELlA, P. B. Direito internacional, terrorismo e aviação civil. São Paulo: Quartier Latin, 2006.

CASELLA, P. B. Fundamentos do direito internacional pós-moderno. Prólogo Hugo Caminos. São Paulo: Quartier Latin, 2008.

CASSESE, Antonio. Le droit international dans un monde divisé. Paris: Berger-Levrault, 1986.

DEGAN, Vladimir-Djuro. L'affirmation des principes du droit naturel par la Révolution française. Annuaire Français de Droit International, v. 35, n. 1, p. 99-116, 1989.

DEGAN, Vladimir-Djuro. Création et disparition de l'état (à la lumière du démembrement de trois fédérations multiethniques en Europe). Recueil des Cours, v. 279, p. 195-375, 1999.

DEGAN, Vladimir-Djuro. On state succession. In: CASELLA, P. B. (Org.). Dimensão internacional do direito: estudos em homenagem a G. E. do Nascimento e Silva. São Paulo: LTr, 2000. p. 118-140. 
DEGAN, Vladimir-Djuro. Some objective features in international law. In: MAKARCZYK, Gerzy. (Ed.). Essays in honour of Krystof Skubiszewski. Haia: Kluwer Law International, 1996. p. 123-146.

DEGAN, Vladimir-Djuro. La succession d'états en matière de traités et les états nouveaux. Annuaire Français de Droit International, v. 42, n. 1, p. 206-227, 1996.

DEGAN, Vladimir-Djuro. Traité et coutume dans le droit de la mer. In: BAPTISTA, L. O.; FONSECA, J. R. Franco da. (Org.). O direito internacional no terceiro milênio: estudos em homenagem ao prof. V. Marotta Rangel. São Paulo: LTr, 1998. p. 407-434.

DUNSHEE DE ABRANCHES, C. A. Espaço exterior e responsabilidade internacional. Rio de Janeiro: Freitas Bastos, 1964.

DUNSHEE DE ABRANCHES, C. A. Proscrição das armas nucleares. Rio de Janeiro: Freitas Bastos, 1964.

DUNSHEE DE ABRANCHES, C. A. Proteção internacional dos direitos humanos. Rio de Janeiro: Freitas Bastos, 1964.

FARO JUNIOR, Luiz. Manual de direito internacional público. Rio de Janeiro: Livraria Martins, 1951.

FAVRE, Antoine. Principes du droit des gens. Fribourg: Libr. de droit et de jurisprudence / Éd. interuniv., 1974.

FRANCHINI NETTO, M. Diplomacia: instrumento da ordem internacional. Rio de Janeiro: Freitas Bastos, 1964.

LA PRADELLE, A. de. Les grands cas de la jurisprudence internationale. Paris: Les éditions internationales, 1938.

LUZ, Nelson Ferreira da. Introdução ao direito internacional público. São Paulo: Saraiva, 1963.

MARINHO, Ilmar Penna. Características essenciais do novo direito internacional. Rio de Janeiro: Imprenta Nacional, 1947.

MARINHO, Ilmar Penna. Tratado sobre a nacionalidade. Rio de Janeiro: Imprensa nacional, 1956.

MATTOS, José Dalmo F. Belfort de. Conceito cristão de guerra. São Paulo: Revista dos Tribunais, 1964. (PUC, tese de titularidade em Direito Internacional).

McWHINNEY, E. The illegal diversion of aircraft and international law. Recueil des Cours, v. 138, p. 261-372, 1973.

MELLO, Celso D. de Albuquerque. Mar territorial. Rio de Janeiro: Freitas Bastos, 1965.

MELLO, Celso D. de Albuquerque. Plataforma continental. Rio de Janeiro: Freitas Bastos, 1965.

MELLO, Celso D. de Albuquerque. Ratificação de tratados. Rio de Janeiro: Freitas Bastos, 1966. 
MELLO, Rubens Ferreira de. Dicionário de direito internacional público. Rio de Janeiro: [s.n.], 1946.

MELLO, Rubens Ferreira de. Tratado de direito diplomático. Rio de Janeiro: Ed. Clássica Livraria, 1948.

MENDES, José. Direito internacional público: prelecções. São Paulo: Duprat \& Comp., 1913.

MENDES, José. Relação entre o direito internacional público e o direito nacional nos países americanos. Revista dos Tribunais, São Paulo, a. 6, v. 24, n. 130, p. 81-84, 1917.

MERCADANTE, Araminta de Azevedo. Processualística dos atos internacionais: Constituição de 1988 e MERCOSUL. In: CASELLA, P. B. et al. (Coord.). Contratos internacionais e direito econômico no MERCOSUL: após o término do período de transição. São Paulo: LTr, 1996. p. 458505 .

NEWMANN, Ralph A. Equity in the world's legal systems. Bruxelles: Bruylant, 1973.

PESSOA, Mário. O direito internacional moderno. Rio de Janeiro: Freitas Bastos, 1947.

RAGAZZI, Maurizio. The concept of international obligations erga omnes. Oxford: Clarendon Press, 1997.

RANGEL, Vicente Marotta. Do conflito entre a Carta das Nações Unidas e os demais acordos internacionais. 1954. (Tese de Livre-Docência) - Faculdade de Direito, Universidade de São Paulo, São Paulo, 1954.

RANGEL, Vicente Marotta. O direito do mar e a sua unificação legislativa entre países de língua portuguesa. In: Estudos em homenagem ao professor A. Ferrer-Correia. Coimbra: Univ. de Coimbra, 1986. v. 1, p. 69-90.

RANGEL, Vicente Marotta. Direito e relações internacionais. 8. ed. São Paulo: Revista dos Tribunais, 2005.

RANGEL, Vicente Marotta. A experiência da conferência da ONU e a Convenção sobre direito do mar. In: NAZO, Georgette N. (Coord.) Questões importantes referentes ao mar. São Paulo: Soamar, 1996. p. 11-18.

RANGEL, Vicente Marotta. Introdução. In: TRINDADE, Antonio Augusto Cançado. Princípios do direito internacional contemporâneo. Brasília: Ed. UnB, 1981. p. v-xiv.

RANGEL, Vicente Marotta. L'avis consultatif du 9 juillet 2004 et l'antinomie entre volontarisme et solidarisme. In: International law and the use of force at the turn of centuries: essays in honour of Vladimir-Djuro Degan. Rijeka: Faculty of Law, Univ. of Rijeka, 2005. p. 199-205.

RANGEL, Vicente Marotta. L'equité en droit international: des développements récents. Tessaloniki: Aristoteleio Panepistimio, 1989. p. 937-950. (separata). 
RANGEL, Vicente Marotta. Natureza jurídica e delimitação do mar territorial. 2. ed. rev. São Paulo: Revista dos Tribunais, 1970.

RANGEL, Vicente Marotta. Objetos culturais: o recente projeto UNIDROIT de convenção internacional. In: BAPTISTA, L. O.; HUCK, H. M.; CASELLA, P. B. (Org.). Direito e comércio internacional: tendências e perspectivas: estudos em homenagem ao prof. Irineu Strenger. São Paulo: LTr, 1994. p. 213-220.

RANGEL, Vicente Marotta. Le plateau continental dans la Convention de 1982 sur le droit de la mer. Recueil de Cours, v. 5, n. 194, p. 269-428, 1985.

RANGEL, Vicente Marotta. Public international law: the last five decades. In: DOLINGER, Jacob; ROSENN, Keith (Ed.). A panorama of Brazilian Law. Miami / Rio de Janeiro: Univ. of Miami North-South Center / Ed. Esplanada, 1992. p. 287-308.

RANGEL, Vicente Marotta. Sobre la efectividad de la justicia en las relaciones internacionales. In: RAMA-MONTALDO, Manuel (Dir.). El derecho internacional en un mundo en transformación: liber amicorum en homenaje al profesor Eduardo Jiménez de Aréchaga. Montevideo: Fundación de Cultura Universitaria, 1994. p. 173-179.

RANGEL, Vicente Marotta. Solução pacífica de controvérsias. In: COMITÊ Jurídico Interamericano (Org.) XI curso de derecho internacional. Washington, D.C.: OEA, 1985. p. 29-49.

REUTER, Paul. Institutions internationales. Paris: PUF, 1955.

RODRIGUES, Horácio Wanderlei. Novo currículo mínimo dos cursos jurídicos. São Paulo: Revista dos Tribunais, 1995.

RUSSOMANO, Gilda. Estudos de direito internacional. Rio de Janeiro: José Konfino, 1956.

SIBERT, Marcel. Traité de droit international public. Paris: Dalloz, 1951. t. 1.

SODER, José. Direitos do homem. São Paulo: Nacional, 1960.

TOMUSCHAT, Christian. International law: ensuring the survival of mankind in the eve of a new century: general course on public international law. Recueil des Cours, v. 281, p. 9-438, 1999.

TOMUSCHAT, Christian. Obligations arising for states without or against their will. Recueil des Cours, v. 241, p. 195-374, 1993.

VALLADÃO, Haroldo. Democratização e socialização do direito internacional. Rio de Janeiro: José Olympio, 1961.

VATTEL, Emer de. O direito das gentes. Prefácio e tradução de V. Marotta Rangel. Brasília: IPRI - UnB, 2004.

VIANNA, Hélio. História diplomática do Brasil. São Paulo: Melhoramentos, 1958. 
